\title{
Experimental Therapeutic Strategies in Epilepsies Using Anti-Seizure Medications
}

This article was published in the following Dove Press journal:

Journal of Experimental Pharmacology

\author{
Fakher Rahim (iD) \\ Reza Azizimalamiri $\mathbb{D}^{2}$ \\ Mehdi Sayyah $^{3}$ \\ Alireza Malayeri ${ }^{4,5}$ \\ 'Molecular Medicine and Bioinformatics, \\ Research Center of Thalassemia \& \\ Hemoglobinopathy, Health Research \\ Institute, Ahvaz Jundishapur University of \\ Medical Sciences, Ahvaz, Iran; \\ ${ }^{2}$ Department of Pediatrics, Division of \\ Pediatric Neurology, Golestan Medical, \\ Educational, and Research Center, Ahvaz \\ Jundishapur University of Medical \\ Sciences, Ahvaz, Iran; ${ }^{3}$ Education \\ Development Center (EDC), Ahvaz \\ Jundishapur University of Medical \\ Sciences, Ahvaz, Iran; ${ }^{4}$ Medicinal Plant \\ Research Center, Ahvaz Jundishapur \\ University of Medical Sciences, Ahvaz, \\ Iran; ${ }^{5}$ Department of Pharmacology, \\ School of Pharmacy, Ahvaz Jundishapur \\ University of Medical Sciences, Ahvaz, \\ Iran
}

\begin{abstract}
Epilepsies are among the most common neurological problems. The disease burden in patients with epilepsy is significantly high, and epilepsy has a huge negative impact on patients' quality of life with epilepsy and their families. Anti-seizure medications are the mainstay treatment in patients with epilepsy, and around $70 \%$ of patients will ultimately control with a combination of at least two appropriately selected anti-seizure medications. However, in one-third of patients, seizures are resistant to drugs, and other measures will be needed. The primary goal in using experimental therapeutic medication strategies in patients with epilepsy is to prevent recurrent seizures and reduce the rate of traumatic events that may occur during seizures. So far, various treatments using medications have been offered for patients with epilepsies, which have been classified according to the type of epilepsy, the effectiveness of the medications, and the adverse effects. Medications such as Levetiracetam, valproic acid, and lamotrigine are at the forefront of these patients' treatment. Epilepsy surgery, neuro-stimulation, and the ketogenic diet are the main measures in patients with medication-resistant epilepsies. In this paper, we will review the therapeutic approach using anti-seizure medications in patients with epilepsy. However, it should be noted that some of these patients still do not respond to existing treatments; therefore, the limited ability of current therapies has fueled research efforts for the development of novel treatment strategies. Thus, it seems that in addition to surgical measures, we should look for more specific agents that have less adverse events and have a greater effect in stopping seizures.
\end{abstract}

Keywords: seizure, epilepsy, experimental therapeutic, drug strategies

\section{Introduction}

Epilepsy is one of the most important diseases of the nervous system that affects $0.5-1 \%$ of people in the community. ${ }^{1}$ Despite significant therapeutic advances in the control of epileptic seizures, in $20-30 \%$ of patients, epileptic seizures are not well controlled, and patients who are controlled with medication(s) are not free from unwanted adverse effects and its various problems. ${ }^{2}$ The symptoms of epilepsy fall in a wide range, of which some people with absence epilepsy stare for a few seconds during a seizure, while others with generalized epilepsies may experience tonicclonic seizures. ${ }^{3}$ Epilepsy is diagnosed based on history, physical examination, and paraclinical tests, in particular, electroencephalography (EEG). Other disorders such as fainting, psychogenic non-epileptic seizures, and transient ischemic attacks should be considered in the differential diagnosis; however, their treatment is different.

Patients with epilepsy face many different challenges. The most significant challenges are: misdiagnosis of epilepsy in a patient who does not really have the
Correspondence: Mehdi Sayyah

Education Development Center (EDC)

Ahvaz Jundishapur University of Medical

Sciences, Ahvaz, Iran

Tel/Fax +986/33367652

Email sayahbargard@gmail.com
Journal of Experimental Pharmacology 2021:13 265-290 
disease misdiagnosis of epilepsy and consequently improper drug selection, refusal to accept medication by the patient, unintended adverse events of antipsychotic medications, medication resistance in the patient, measures other than medical therapy and its limitations, photosensitivity, age and epilepsy problems in children and the elderly, epilepsy and pregnancy, and sudden death in epileptic patients. In this review, we will collect and compile the treatment problems of these patients, as well as review the therapeutic approach using anti-seizure medications in patients with epilepsy.

\section{Epidemiology and Etiology}

Around 50 million people worldwide have epilepsy, but its distribution varies across countries. The prevalence of epilepsy is higher in developing countries than in developed countries. The annual incidence rate of epilepsy is between $18.9 \%$ and $19 \%$. The estimated annual incidence is $70-40$ per 100,000 person-years in developed countries and 100 per 100,000 person-years in developing countries. ${ }^{4}$ Recently, GBD 2017 US Neurological Disorders Collaborators estimated the incidence, prevalence, mortality, and disability-adjusted life-years (burden) of epilepsy among the 48 contiguous states and showed that eastern states had higher rates of idiopathic epilepsy. ${ }^{5}$ Similarly, Deuschl et al compared the burden of epilepsy in the EU between 1990 and 2017 with those of the WHO European region and worldwide and showed that the disease's prevalence and burden would likely increase with the progressive ageing of the European population. ${ }^{6}$

The highest age-adjusted incidence rate is observed in children and older people. Approximately $50 \%$ of all cases of epilepsy occur both in children and in adults, and the incidence is slightly higher in men compared to women and tends to peak in the elderly. ${ }^{7}$ Indeed, the trend over the past thirty years has shown a decrease in the incidence of epilepsy in children and an increasing pattern in adults. The reason for this is not entirely clear, but the decrease in the trend in children can be due to a healthy lifestyle, better care, and increase immunization programs during pregnancy. ${ }^{8}$ During pregnancy and childbirth, these quality health care can reduce brain damage, congenital hypoxia, and viral infections of the central nervous system (CNS). ${ }^{9}$ The increased incidence of epilepsy in the elderly can be attributed to increased age-related epileptogenic conditions. ${ }^{10}$ Around $75 \%$ of the 60 million patients with epilepsy reside in resource-limited areas in developing countries with poor diagnostic services and treatment facilities. ${ }^{11}$ A large proportion of these patients may not receive appropriate treatment, which is called the "treatment gap" because there is low availability of anti-seizure medication or do not follow or adhere to the cultural, economic, or socio-political factors. ${ }^{12}$

Researchers have linked certain types of epilepsy to genetic changes; however, it is estimated that from about 100 to more than genes may be associated with epilepsy. ${ }^{13}$ Consequently, specific genes can make a person more sensitive to environmental conditions resulting in epilepsy or trigger seizures. Traumatic brain injury (TBI), brain diseases such as tumors or strokes that lead to brain damage can also lead to epilepsy. ${ }^{14}$ Stroke is also one of the major causes of epilepsy in adults over 35 years of age. Infectious diseases such as meningitis, acquired immunodeficiency syndrome (AIDS), and viral encephalitis can also lead to epilepsy. ${ }^{15,16}$ Neonates during prenatal period are susceptible to brain damage that can be caused by several factors, including maternal infections, malnutrition, or intermittent hypoxia. ${ }^{17}$ Finally, epilepsy can sometimes be associated with developmental disorders, such as autism and different kind of neuro-cutaneous disorders. ${ }^{18}$

\section{Pathophysiology}

All the seizures occur when a part of the brain (mainly the cortex) produces abnormal, paroxysmal, and recurrent discharges. Although seizures' pathophysiology is different in genetic and acquired epilepsies, in all kinds of epilepsies, from genetic epilepsies to post-traumatic ones, the cortex produces these abnormal, paroxysmal, and recurrent discharges. In genetic epilepsies with the malfunctioning of voltage-gated or ligand-gated channels, the defected neurons are prone to produce abnormal discharges. In acquired epilepsies such as post-traumatic, the neurons' environment will change in a way that reduces the threshold of neurons to produce abnormal and recurrent discharge. $^{19}$

The pathophysiology of epilepsy is usually seen as an imbalance between $\gamma$-aminobutyric acid (GABA) inhibitor and glutamate-stimulating neurotransmission. ${ }^{20}$ This change is due to the selective loss of GABA-ergic inhibitory neurons after deposition of epileptic insults (eg, epilepsy, stroke, and damaged brain injury) and the reorganization of neural circuits over-synchronize neural cells population. Deficiency in the signaling of GABA, and increased glutamatergic transmission, which has been reported in many types of epilepsy, are considered as the basis of epilepsy pharmacotherapy. ${ }^{21,22}$ 
Another mechanism is Neurotransmitters and Drug Abuse (NMDA). NMDA excessive activity triggers neurons with potentially toxic concentrations of calcium and sodium. Glutamate-NMDA interactions lead to apoptosis, which may be closely involved in the pathophysiology of epilepsy. Despite the advantages of glutamate blockage in various disorders, deficiency of the NMDA activity can be deleterious.

There are many specific pathophysiologic defects leading to epilepsy at various levels of brain functions, such as neuronal network and structure, neurotransmitter receptors and synthesis, synaptic development, and ion channels Different underlying mechanisms, like altered neuronal circuits, abnormal structure of dendrites and dendritic spines, decreased GABA synthesis, abnormal GABA receptor subunits, and excess glycine lead to overactivation of NMDA receptors, and potassium channel mutations. ${ }^{23}$

\section{Challenges of Epilepsy Treatment Diagnostic Error}

It is clinically essential to differentiate epilepsy from other conditions mimicking seizures, especially in emergencies, and there are several ways to diagnose it. One of the proposed diagnostic methods is the measurement of creatine kinase (CK) enzyme, which increased epilepsy, but it is not a specific test. ${ }^{24}$ Lahat et al found an increase in serum CK in children admitted following an episode of febrile convulsions. ${ }^{25}$ Brigo et al, in a systematic review of four studies, comprising a total of 343 cases, reported that CK could provide valuable retrospective information at the later stages of the differential diagnosis between convulsive and non-convulsive cases. ${ }^{26}$ Nass et al retrospectively studied laboratory markers of cardiac and metabolic complications after generalized tonic-clonic seizures in 223 patients of 986 screened cases, and showed that increased troponin associated with seizure is among the more frequent complications following emergency admissions. ${ }^{27}$ Dafotakis et al evaluated the serum lactate and CK levels at admission and 10-48 $\mathrm{h}$ after the seizure episodes, respectively, and reported that these biomarkers were significantly increased in patients with epilepsy. ${ }^{28}$ Although several studies have concluded that after seizure, various reported biomarkers increased significantly, the question arises as to whether tonic or clonic movements will cause muscle damage and, consequently, increase this biomarker. Previous studies with this background have considered different groups such as psychogenic non-epileptic seizures, vasovagal syncope, and transient loss of consciousness, which are also likely to cause muscle damage in these disorders, as a control group. However, in comparison, still in the group of seizures, these biomarkers had a significant elevation. ${ }^{29,30}$

A number of studies showed that some bias exists in the diagnosis of epilepsy, which has been studied so far. Therefore, it is understood that physicians may be biased in diagnosing epilepsy; although, the studies suggest that general misdiagnosis of epilepsy may not be a rare occurrence. ${ }^{31}$ These diagnostic errors may also overshadow the global picture, as emphasized, and will be detrimental to patient care. As a result, the general misdiagnosis of epilepsy has probably been underestimated. It is a matter of recognizing important factors that may lead to such diagnostic errors.

\section{Diagnostic Evaluation Medical History}

Epilepsy is a clinical diagnosis based on the patient's history; so, all neurological imaging or examination and electroencephalographic findings can be normal in patients with epilepsy. Diagnosis is often difficult in patients with suspected epilepsy, and about $20 \%$ of all patients referred to diagnostic centers may incorrectly be considered as epilepsy. ${ }^{31,32}$ In most cases, the diagnosis of epilepsy is critical and depends on the description of the attack by a witness, but the accuracy and validity of this part of the diagnostic procedure are largely unknown. ${ }^{33}$ Thus, when there is structural brain damage, treatment is continued for a lifetime, and in cases, the cause of epilepsy is idiopathic (genetic), depending on the case, treatment should be given for two to five years. Therefore, before starting treatment, it is necessary to make a correct diagnosis. Although the accuracy of witness descriptions varies widely, it should be noted that it has important clinical implications. Diagnosis of epilepsy affects almost all aspects of a patient's life, and the classification of the disease also affects the choice of antiepileptic drugs (AEDs), which usually is a long-term drug therapy.

Therefore, in patients who do not achieve complete seizure control, factors other than predisposing factors in the development of epileptic seizures may are responsible, which require differential diagnoses. One of the diseases is syncope, which is a temporary loss of consciousness usually related to insufficient blood flow to the brain, which should be differentially diagnosed from epilepsy 
according to medical history and examination. ${ }^{34}$ Other diseases, such as migraines, can cause loss of consciousness due to deficiency of minerals and nutrients, vasomotor disorders, and massive vegetative disturbances. ${ }^{35}$ Some brain damages, such as brain infections, brain tumors, and high cranial pressure, can cause loss of consciousness with or without seizures that should be differentially diagnosed from epilepsy. ${ }^{36}$ So, medical history and differential diagnosis are fundamental in the treatment choice for epilepsy. ${ }^{37}$

\section{Neurological Examination}

Diagnosis of neurological diseases, such as epilepsy, is usually based on the proper combination of patient history and neurological examination. ${ }^{38}$ Obtaining an accurate neurological examination is the most important factor in achieving a correct diagnosis and using the appropriate treatment. To diagnose epilepsy, a neurological examination is performed, which includes questions and activities to see how the body responds. A neurological examination comprises numerous procedures to diagnose epilepsy. This evaluation usually begins with a few simple questions and other mental assessment tests, which can help determine the possible brain damage. In these tests, the doctor assesses the patient's thinking, memory, and speech skills. These tests help to determine the damaged areas of the brain and also brain's functional capacity in patients with epilepsy. ${ }^{39}$

\section{Electroencephalography (EEG)}

This is the most commonly used test for diagnosing epilepsy, in which electrodes were attached to the scalp using adhesive-like materials and recorded the brain's electrical activity. ${ }^{40}$ Recording seizures helps to determine the type of seizure as well as rules out other possible diseases. The doctor may recommend instructions to provoke epileptiform discharges, such as sleep deprivation shortly before the test. Bouma et al in a diagnostic test accuracy metaanalysis on 15 studies with a total of 1799 participants, reported the sensitivity and specificity of routine EEG after a first unprovoked seizure which were $17.3 \%$ and $94.7 \%$, respectively. ${ }^{41}$ Gilbert et al, in a diagnostic test accuracy meta-analysis on 25 studies involving 4,912 EEG, showed Specificity (range 0.13 to 0.99 ) and sensitivity (range 0.20 to 0.91$).{ }^{42}$

\section{Laboratory Examination}

To diagnose this condition, the physician will review the symptoms and medical history of a person and perform several tests to diagnose epilepsy and determine the cause of the seizures. ${ }^{43}$ The first diagnostic method is a neurological examination in which the doctor may examine behavior, motor ability, mental function, and other areas to diagnose the disease and determine the type of epilepsy. ${ }^{44}$ Blood tests may also be done to check for signs of infection, genetic predisposition, or other seizurerelated illnesses. Most of the diagnostic accuracy studies showed relatively low sensitivity and high specificity for laboratory biomarkers in patients with epilepsy (Table 1). Thus, laboratory tests have a low ability to correctly identify those patients with epilepsy and a relatively high ability to identify those patients without the disease precisely. ${ }^{45}$ Among various laboratory biomarkers, prolactin had sensitivity and specificity of $47-93 \%$ and 74-98.2\%, respectively, while creatine kinase had sensitivity and specificity of $19-87.5 \%$ and $86.7-100 \%$. Consequently, ammonia showed sensitivity and specificity of $53-55 \%$ and $90-100 \%$, respectively. Though these findings suggest that these laboratory biomarkers' serum level increases after an epileptic seizure, they can be used to

Table I Overview of Studies Investigating Elevations of Various Laboratory Biomarkers in Patient with GTCS

\begin{tabular}{|c|c|c|c|c|c|c|}
\hline Author, Year & Population & Age & Setting & Lab Biomarker & Sensitivity & Specificity \\
\hline Ehsan, $1996^{149}$ & 50 (I3 GTCS) & $6-61$ & Prospective & Prolactin & $76.9 \%$ & $85.7 \%$ \\
\hline Alving, $1998^{150}$ & 58 (I6 GTCS) & $13-68$ & Prospective & Prolactin & $93 \%$ & $74 \%$ \\
\hline Shah et al, $2001^{151}$ & 89 (36 GTCS) & $18-62$ & Prospective & Prolactin & $47 \%$ & $98.2 \%$ \\
\hline Willert et al, $2004^{29}$ & 60 GTCS & $18-62$ & Prospective & Creatine kinase & $19 \%$ & $100 \%$ \\
\hline Chen et al, $2005^{30}$ & Pooled analysis & - & Meta-analysis & Prolactin & $60 \%$ & $95.9 \%$ \\
\hline Holtkamp et al, $2006^{152}$ & 16 GTCS & $18-77$ & Retrospective & Creatine kinase & $87.5 \%$ & $87.5 \%$ \\
\hline Goksu et al, $2009^{153}$ & 63 (26 GTCS) & $16-78$ & Prospective & Creatine kinase & $34.6 \%$ & $89.2 \%$ \\
\hline Yanagawa et al, $2007^{154}$ & 16 GTCS & $7-81$ & Prospective & Creatine kinase & $40 \%$ & $86.7 \%$ \\
\hline Liu et al, $2010^{155}$ & 31 GTCS & $>18$ & Prospective & Ammonia $(\mathrm{NH} 3)$ & $54.8 \%$ & $100 \%$ \\
\hline Tomita et al, 201 I ${ }^{156}$ & 207 GTCS & $>16$ & Retrospective & Ammonia (NH3) & $53 \%$ & $90 \%$ \\
\hline
\end{tabular}


detect epilepsy. They are not a useful method for the differentiation of different forms of epileptic seizures. ${ }^{46,47}$

Imaging

Imaging is central to the assessment of patients with epilepsy and has dramatically modified their management.

\section{Computed Tomography Scan (CT Scan)}

CT-scans use X-rays to create a cross-sectional image of the brain. This imaging technique can detect brain abnormalities, such as tumors, bleeding, and cysts, leading to seizures. ${ }^{40}$

\section{Magnetic Resonance Imaging (MRI)}

MRI uses strong radio and magnetic waves to evaluate and record the details of the brain. The doctor may be able to diagnose injuries or abnormalities in the brain that can cause seizures. ${ }^{48}$

\section{Functional MRI (fMRI)}

fMRI measures the amount of changes in blood flow that occur inactive parts of the brain. Prior to surgery, physicians can use fMRI to pinpoint the exact location of vital functions, such as speaking and moving (eloquent cortex), which prevents the surgeon from damaging these sites during surgery of epileptic patients. ${ }^{49}$

\section{Positron Emission Tomography (PET)}

PET scans use low-dose radioactive material that enters a vein and helps identify active areas of the brain as well as diagnose abnormalities. ${ }^{50}$

\section{Single Proton Emission Computed Tomography (SPECT)}

This test is mainly used when MRI and EEG have not been able to detect the source of seizures in the brain. ${ }^{51}$ The SPECT test uses a small amount of radioactive material that is infused into a vein and provides a detailed three-dimensional map of blood flow activity in the brain during a seizure. Physicians may also perform a type of SPECT test in addition to magnetic resonance imaging (called SISCOM), which provides more detail and may lead to the detection of epileptogenic lesion or zone.

\section{Genetic Testing}

A new study shows that common genetic testing can diagnose epilepsy in children with seizures. Genetic testing should be included in the initial assessment of young children with epilepsy, and through the detection of the type of epilepsy helps to choose the most effective treatment to control the disease. ${ }^{52}$ According to the researchers, genetic information helps identify which drugs may help treat the disease and which drugs should be avoided. ${ }^{53,54}$ Recent researches showed that genetic testing using next-generation sequencing (NGS) provided a diagnosis in $14.9-24.4 \%$ of individuals with epilepsy. ${ }^{55}$ Sánchez Fernández et al, in a meta-analysis, compared the cost-effectiveness of genetic testing strategies involving 3 different genetic tests, including chromosomal microarray (CMA), epilepsy panel (EP) with deletion/duplication testing, and whole-exome sequencing (WES) in patients with epilepsy of unknown etiology. They showed that WES and $\mathrm{EP}$ are the most cost-effective genetic tests for epilepsy. ${ }^{56}$ Although genetic testing is expensive and difficult to obtain, in some kind of epilepsies may result in a definitive diagnosis and may also help choose the most appropriate medication.

\section{Epilepsy Treatment Methods}

Various treatment modalities for adequate seizure control in patients with epilepsy, include anti-seizure medications (ASMs), surgical procedures, vagus nerve stimulation (VNS), and ketogenic diet (high fat and low carbohydrate diet). More than $70 \%$ of patients with epilepsy are controlled with AEDs. ${ }^{57}$ These agents prevent seizures but do not cure epilepsy. Several types of medication that are used in a person depend on the type of seizure. In a small group of patients, especially those with focal epilepsy as well as generalized ones, surgery may be helpful. ${ }^{58}$ VNS is a relatively new treatment for epilepsy and helps reduce the number, duration, and severity of seizures. ${ }^{59}$ In this method, the left vagus nerve will be stimulated using slight electrical discharges. This method does not cure the person, and the person often needs to repeat this treatment. For children whose seizures are not controlled by medication, another way to help is to use a ketogenic diet (high fat and low carbohydrate diet). ${ }^{60}$

\section{Prevention and Control Measures in Epilepsy}

Epilepsy has primary and secondary causes, which are caused by various reasons such as drowning, swallowing a foreign body, brain damage, central nervous system infections, road accidents, etc. and cause It is possible for a child who is living in normal conditions and with good genetics to become an epileptic child. Epilepsy due to secondary factors is preventable; therefore, taking 
hygienic measures such as washing hands, taking care not to transmit infections, and maintaining the body's immunity could be effective in people's health against epilepsy. ${ }^{61-65}$ Prevention of the known causes of epilepsy most likely includes prevention of birth trauma, central nervous system (CNS) infection in children, cerebrovascular disease in adults, and alcohol and heroin abuse. In most patients with anthrax, proper use of AEDs can prevent recurrence of seizures or premature death. At least $70 \%$ of patients with a single seizure do not have a recurrence and should not be considered as patients with epilepsy. ${ }^{66}$ Most people treated for epilepsy (70\% to $80 \%$ ) will not experience more seizures while using medication(s), and up to $70 \%$ of children in this group will not have seizures even after stopping medication. ${ }^{67}$ Patients with recurrent seizures who have been treated for 5 years and children with mental retardation or cerebral palsy are less likely to outgrow seizures. ${ }^{68}$ Epilepsy must be diagnosed and treated in a timely manner; therefore, the disease should etiologically observe in order to reach a proper diagnosis and treatment, and then use drugs that had the least adverse events and maximum efficacy to control this disease. ${ }^{69}$

In a meta-analysis of 17 randomized clinical trials on preventive methods against sudden unexpected death in epilepsy (SUDEP), Maguire et al found only very lowquality evidence of a preventative effect for nocturnal supervision. $^{70}$ SUDEP is defined a sudden, unexpected death, non-traumatic or non-drowning in people with epilepsy, with or without evidence of epileptic seizures, and no other cause for death during post-mortem examination. SUDEP is the most common cause of death associated with epilepsy, with about 1 to 2 deaths per 1,000 patients per year; so, overall, the risk of SUDEP is more than 20 times higher than that in the general population. ${ }^{71}$ Recurrent seizures, male gender, young age at the first seizure, prolonged duration of epilepsy, and multiple AEDs are thought to increase the risk of SUDEP. The exact cause of SUDEP is currently unknown; however, it is thought to be associated with heart failure, respiratory problems, and brain damage following seizure. ${ }^{72}$

Ryvlin et al, in a meta-analysis pooling data from 112 randomised placebo-controlled trials in patients with refractory epilepsy, showed that SUDEP was significantly less common in the patients receiving efficacious AEDs than in the placebo group. ${ }^{73}$ Later on, Hesdorffer et al, in a meta-analysis of combined data from the three casecontrol studies alongside data on the frequency of GTCS and AED therapy, showed that not a single drug of the AEDs was associated with increased SUDEP risk once GTCS occurrence was taken into account. They gave a consistent message that increases SUDEP risk is associated with increasing the number of GTCS and not AEDs. ${ }^{74}$ In another meta-analysis conducted by Hemery et al, on 72 randomized controlled trials of adjunctive AEDs, existing evidence does not support robust differences between these drugs to prevent secondary GTCS. ${ }^{75}$ Recently, in a Maguire et al, in a comprehensive and latest updated Cochrane meta-analysis on 1277 records (randomised controlled trials, cohort, case-control, and nonrandomised studies) found a preventative effect for nocturnal supervision against SUDEP with a recommendation of the need for more research to pinpoint the efficacy of further interventions, such as early surgical evaluation, seizure detection devices, selective serotonin reuptake inhibitors (SSRIs), opiate and adenosine antagonists safety pillows, and educational programs to prevent SUDEP. ${ }^{76}$

\section{Risk Factors for Epilepsy}

Epilepsy is associated with various risk factors, including strongly, moderately, weakly, and probably related (Table 2).

High-risk factors for epilepsy include anoxia (lack of oxygen) and birth trauma, congenital anomalies, structural abnormalities of the brain in infants, mental retardation, cerebral palsy (CP), CNS infections (such as bacterial meningitis and viral encephalitis) in children, moderate to severe stroke, especially in men aged 15 to 35 years, cerebrovascular disease (CVD) and Alzheimer's disease in the elderly, ${ }^{36,77}$ Moderate risk factors for epilepsy include a family history of epilepsy, especially in siblings, in parents or first-degree relatives, ${ }^{78}$ and brain tumors and surgeries in any age group, multiple sclerosis (MS), ${ }^{79}$ and chronic alcohol or heroin abuse. ${ }^{80}$ Suspected risk factors include febrile seizures in children (maybe because of genetic predisposition in some kind of epilepsies that begin with febrile seizures), harmful events around birth without $\mathrm{CP}$, immunity against whooping cough (pertussis), mild head trauma, and non-purulent meningitis. ${ }^{81}$

\section{Selection of Medication Based on the Type of Epilepsy}

Knowing the type of epilepsy is the first indicator for choosing an appropriate AEDs. Some types of epilepsy are controlled with certain medications. Ethosuximide, for 
Table 2 Modifiable Risk Factors for Epilepsy

\begin{tabular}{|l|c|}
\hline At-Risk Group & Risk Factors \\
\hline Strong (Relative Risk> 4) & $\begin{array}{c}\text { Anoxic } \\
\text { Congenital anomalies } \\
\text { Structural abnormalities of the brain }\end{array}$ \\
\hline Children & $\begin{array}{c}\text { Mental retardation } \\
\text { Cerebral palsy }\end{array}$ \\
\hline Adults & Central nervous system infection \\
\hline Elderly & Cerebrovascular disease \\
\hline \multicolumn{2}{|c|}{ Moderate (Relative Risk 4-2) } \\
\hline Wdults & Chronic alcohol and heroin use \\
\hline \multicolumn{2}{|c|}{ Mrobable brain injury } \\
\hline \multicolumn{2}{|c|}{ Does not have } \\
\hline \multicolumn{2}{|c|}{ Immunization against pertussis } \\
\hline \multicolumn{2}{|c|}{ Mild injury } \\
\hline
\end{tabular}

example, can only inhibit small primary epilepsy, while it may aggravate seizure. ${ }^{82}$ Phenytoin and vigabatrin may also implicate in worsening of seizures, specially generalized type. ${ }^{83}$ Therefore, the purpose of controlling epilepsy with medication is to prescribe AEDs suitable for the type of epilepsy. Problems in this area can be categorized as follows:

In most cases, when seizures are happening, the doctor will often not present, especially a neurologist, and should be commented based on the patient or companion's descriptions. It should be borne in mind that the patient or companions may not pay attention to certain conditions and may not be able to describe the patient's condition and epileptic seizures properly adequately.

\section{Pharmacological Treatment}

The treatment process usually starts with medication. If medications do not cure the disease, therapist may suggest surgery or other treatments. Most people with epilepsy are treated with anti-seizure medications (ASMs). Taking medicines in some patients reduces the frequency and severity of seizures. Therapist will advise the patient on when to stop taking medicine. More than half of children with epilepsy who no longer experience epilepsy-related symptoms even after stopping medication can spend the rest of their lives without medication. Many adults can also stop taking the drug without experiencing a seizure after two or more years of life. Finding the right drug and dosage is a complex task. Therapist will consider patient's condition, frequency of seizures, age, and other factors when choosing medication. Physicians may also review other medications you are taking to ensure these medications do not interfere with anti-seizure medication. The doctor will first prescribe a low-dose drug and gradually increase the dose until the seizures are properly controlled.

AEDs are associated with adverse events. ${ }^{84}$ Mild adverse events include fatigue, dizziness, weight gain, decreased bone mass density (BMD), eczema, ataxia, dysphonia, and lethargy. More severe but rare adverse events include depression, suicidal ideation, self-injurious behaviors, severe eczema, and organ-specific inflammatory response. At least half of newly diagnosed patients recovered from seizures when they received their fist medication.

\section{Older vs Newer Antiepileptic Drugs (AEDs)}

The efficacy and adverse effects of AEDs may vary between new and old drugs. ${ }^{85}$ Newer AEDs, defined here arbitrarily as those coming on the market after introducing carbamazepine (1993-2019), may have advantages over older drugs (Figure 1). Patients who are well controlled with older AEDs are sometimes shifted to newer AEDs because they are more desirable in terms of long-term adverse events, ie, less prevalent neurological adverse reactions, less frequent osteoporosis, and better immunity during pregnancy. ${ }^{86}$ However, there is a serious concern that the efficacy of newer AEDs, both for new-onset epilepsy and chronic refractory epilepsy, is not better than that of older drugs. ${ }^{87}$

\section{Anti-Epilepsy Drugs (AEDs)}

AEDs suppress the abnormal activity of neurons called epileptic discharges, which is a limited period of abnormal discharge of brain neurons. Three mechanisms of AEDs action have been proposed so far, including modulation of sodium, calcium, or potassium-dependent voltage channels, increased synaptic pathway by GABA, and reduced glutamate-induced stimulation (Figure 2).

Because AEDs are often used for a long time, it is important to consider their pharmacokinetic properties to 


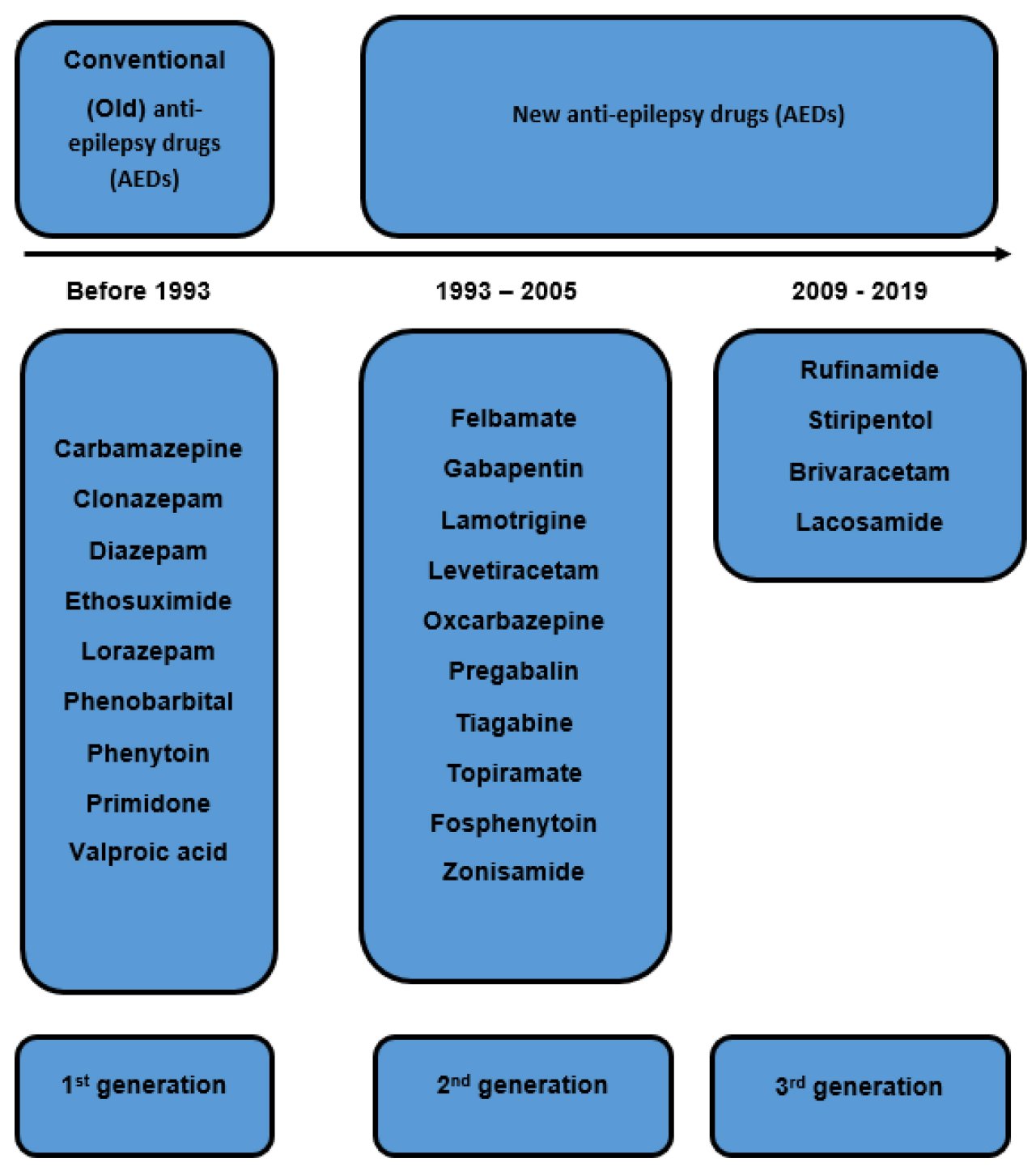

Figure I lllustration of old vs new, as well as the first to third generation of anti-epilepsy drugs.

avoid adverse events and drug interactions. In the case of some of these drugs (such as phenytoin), achieving optimal therapeutic goals requires determining the blood level and drug clearance. ${ }^{88}$ AEDs are generally well absorbed orally and have good bioavailability. Most AEDs, except gabapentin and vigabatrin, have a hepatic metabolism; also, some of these drugs are converted to active liver metabolites. AEDs resistance may result from an increase in drug delivery in the blood-brain barrier (BBB) region. ${ }^{89}$ Blood concentrations of AEDs may reach toxic and dangerous levels in the presence of drugs that inhibit the metabolism of these drugs or drugs that cause them to separate from plasma protein binding sites..$^{90}$ On the other hand, drugs that are involved in inducing hepatic metabolizing enzymes (such as rifampin) reduce the blood levels of these drugs to the point that they are no longer sufficient to control seizures. Many anticonvulsant drugs themselves are able to stimulate the hepatic metabolism of drugs. The most important of these are carbamazepine and phenytoin. ${ }^{91}$ Identifying specific types of epilepsy is very important for prescribing appropriate AEDs (or a combination of drugs). The choice of drug is usually made based on its known beneficial effects on the specific type of epilepsy diagnosed, the patient's prior response, and adverse events of the drug. Treatment usually involves a combination of medications and the addition of effective medications if previous medications are not enough. ${ }^{92}$ Long-term therapy with AEDs in women is associated with certain adverse events, which the most important of these complications is teratogenicity. ${ }^{93}$ Children born to 


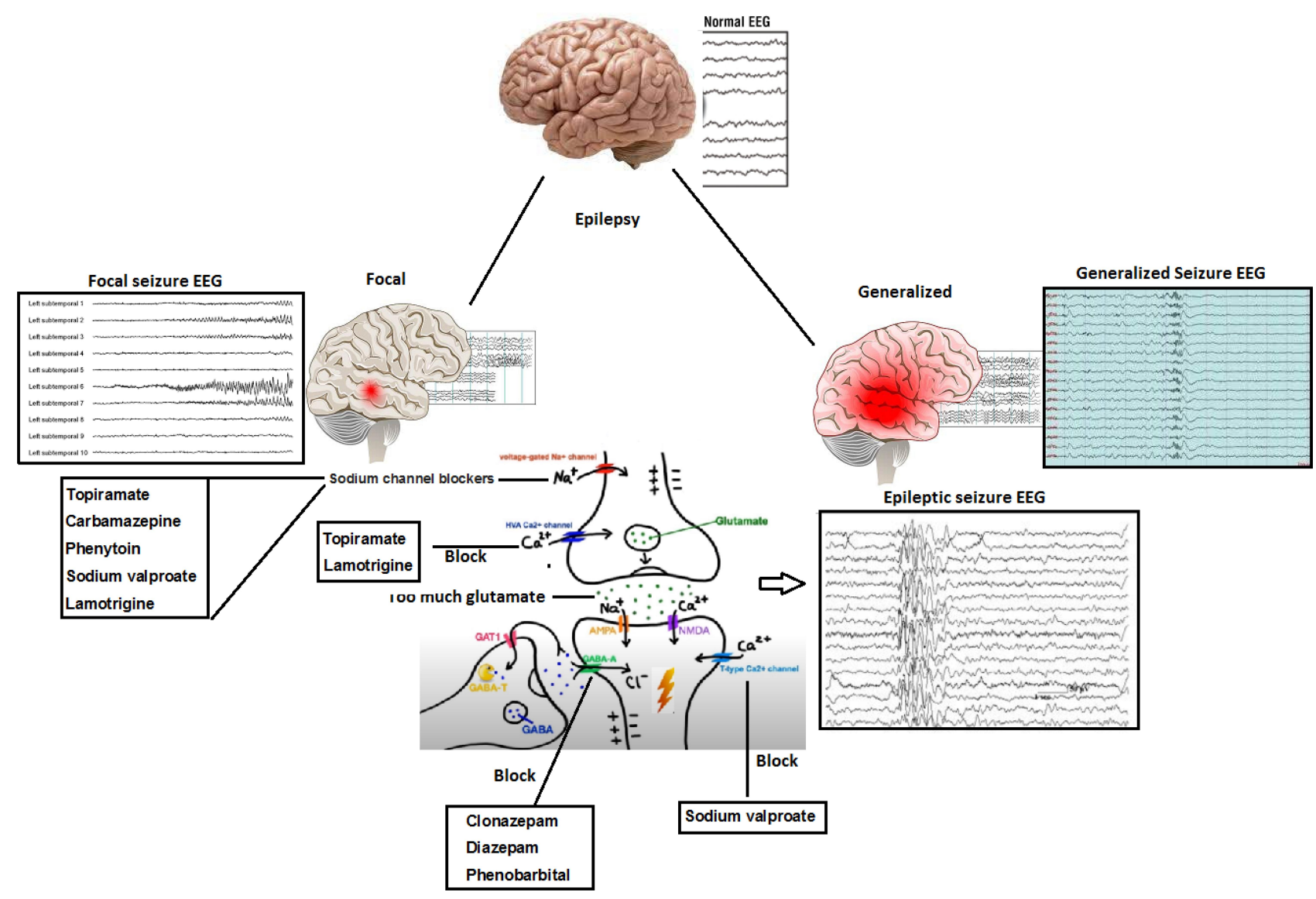

Figure 2 Different mechanisms of AEDs action.

mothers taking anticonvulsant drugs during pregnancy are at increased risk for congenital disabilities. ${ }^{94}$ Neural tube defects (NTD) have been shown to be highly associated with valproic acid intake. ${ }^{95}$ Carbamazepine is known to cause cranial and facial abnormalities and spina bifida, and a fetal hydration syndrome (FHS) has been described in pregnant women after taking phenytoin. ${ }^{96}$

\section{Voltage-Dependent Sodium Channel Blockers}

This class of AEDs includes phenytoin, carbamazepine, zonisamide, and lamotrigine. These agents block voltagedependent sodium channels in neuronal membranes.

\section{Phenytoin}

Phenytoin is used to control all types of epilepsy except myoclonic seizures, trigeminal neuralgia, epilepsia partialis continua, cardiac arrhythmias, and to accelerate wound healing (topically). It exerts its anticonvulsant effect at therapeutic concentrations by blocking sodium channels and inhibiting repetitive action potential. Phenytoin also inhibits the release of serotonin and norepinephrine and affects other neurotransmitters' concentration. ${ }^{97}$ Phenytoininduced adverse events include nausea, vomiting, disturbance of consciousness, dizziness, headache, tremor, irritability, insomnia, rarely dyskinesia, peripheral neuropathy, imbalance, impaired speech, constant and involuntary movements of the eyes back and forth, blurred vision, skin rash, enlargement facial combination, hair loss, acne, fever and hepatitis, arrhythmias, skin necrosis, lymphadenopathy and gingival hypertrophy. ${ }^{98}$

\section{Carbamazepine}

Carbamazepine is prescribed to treat certain conditions such as neurological pain (trigeminal neuralgia, diabetic neuropathy), epilepsy (focal and non-primary generalized), and bipolar disorder. Carbamazepine is an anticonvulsant that reduces nerve tics that cause pain and seizures. This drug is one of the AEDs that is used for behavioral and stress disorders. ${ }^{99}$ Carbamazepine-induced adverse events include dizziness, lethargy, difficult balancing and walking, nausea, vomiting, irregular heartbeat, shortness of breath, liver problems, and fainting. ${ }^{100}$ 


\section{Topiramate}

Topiramate is an anticonvulsant, which is used to treat seizures in adults and children. Extended-release topiramate is used in adults and children six years of age and older. Topiramate is a type of AEDs that is prescribed to control seizures and migraines. Topiramate helps control seizures by reducing the abnormal electrical current in brain cells. The exact anticonvulsant mechanism and other topiramate effects are not yet well known; however, preclinical studies have identified four characteristics that may be related to the effect of topiramate for epilepsy. ${ }^{101}$ Electrophysiological and biochemical evidence shows that topiramate inhibits voltagedependent sodium channels in a concentration-dependent manner, increases the neurotransmitter activity of gamma aminobutyrate in some GABA-A receptor subtypes, antagonizes AMPA/kainate subgroup of glutamate receptor, and inhibits the carbonic anhydrase (CA) enzyme, especially isozymes II and IV. ${ }^{102,103}$ Adverse events of topiramate include nausea and vomiting, constipation, diarrhea, paresthesia, cognitive impairment, headache, dizziness, ataxia, drowsiness, weakness, blurred vision, diplopia, nystagmus, loss of appetite, weight loss, kidney stones, osteomalacia. Rare adverse events include metabolic acidosis, hyperthermia, acute glaucoma, oligohydrosis, and bone marrow failure. ${ }^{104}$

\section{Lamotrigine}

It is an AED or anticonvulsant drug. This drug is used alone and sometimes combined with other drugs to treat epileptic seizures in adults and children older than 2 years. It is also used to reduce psychological attacks in adults with bipolar disorder. Lamotrigine may be used for purposes other than those used in these cases. Indications: This drug is used to treat focal seizures and focal to bilateral tonic-clonic seizures. It may have adverse events, such as dizziness, lightheadedness, drowsiness, nausea, blurred vision, weight loss, weakness, etc., which are not very dangerous and may gradually become addictive. ${ }^{105,106}$ However, skin-elated adverse events of this drug, although rare, can be hazardous and the patient needs to be vigilant and careful about it. This condition, known as Stevens-Johnson syndrome, manifests itself in the form of skin blemishes and rashes, fever, sore throat, and cold symptoms, and progresses rapidly and affects all areas of the skin. ${ }^{107}$

\section{Calcium Channel Blockers}

This group of drugs, such as ethosuximide, valproic acid, gabapentin, and pregabalin, inhibits low-threshold calcium channels (type T).

\section{Ethosuximide}

Ethosuximide is the choice of medication in the absence of epilepsy. All medications can cause adverse events, but many consumers do not experience any adverse events when they were taking ethosuximide. In case of persistent adverse events, the doctor should be informed when symptoms, such as feeling sick, abdominal pain, headache, dizziness, fatigue and drowsiness, diarrhea, loss of appetite, restlessness, skin rash, and mood changes occur. Glauser et al, in a double-blind, randomized controlled clinical trial using optimal initial monotherapy of ethosuximide for 453 children with newly diagnosed childhood absence epilepsy (CAE) during 12 months, reported a superior effectiveness of ethosuximide compared to other AEDs without intolerable adverse events. ${ }^{108}$ Shatara et al and Werbel et al, assessed the effect of fluoxetine, on the protective action of two commonly used AEDs, including ethosuximide (ETX) and valproate (VPA) in animal model. It should be noted that ethosuximide may cause blood disorders; although this is a very rare complication, patient needs immediate medical care if having other symptoms such as fever, mouth sores, bruising, or unexplained bleeding. ${ }^{109,110}$ Veroniki et al, in a systematic review and meta-analysis on experimental and observational studies, reported that ethosuximide (OR, 3.04; $95 \%$ CI, 1.23-7.07) was significantly more harmful in pregnant women with epilepsy than control. ${ }^{111}$

\section{Sodium Valproate}

Sodium valproate was accidentally discovered in France in the 1960s to be useful in treating epilepsy. Today, it is used in almost all kinds of epilepsies. However, this drug is effective in all types of epilepsy. In children under three years of age, it is necessary to use this drug with caution because it sometimes causes severe liver damage. ${ }^{112}$ Some people develop low blood platelets with this drug. The most common adverse events of sodium valproate are gastrointestinal irritation, hair loss, tremors, ankle swelling, weight gain, and drowsiness, especially if taken with phenobarbital. ${ }^{107}$

\section{Gabapentin}

Gabapentin is an AED or anticonvulsant drug that acts on the chemicals and nerves that cause seizures and pain. It is used in adults to relieve nerve pain caused by the herpes virus. ${ }^{105}$

\section{GABA-A Channel Blockers}

Benzodiazepines interact with specific receptors on the GABA-A-chlorine channel receptor. Benzodiazepines can 
increase the frequency of chlorine channel opening and the inhibitory effect of GABA. Phenobarbital and other barbiturates increase the inhibitory effect of GABA. Vigabatrin and valproic acid irreversibly inhibit GABA aminotransferase, an important enzyme that terminates the GABA effect. GABA is a structural analogue of GABA but does not directly activate GABA receptors. Other drugs that can facilitate the inhibitory effects of GABA include Felbamate, topiramate, and valproic acid.

\section{Diazepam}

Diazepam is a sedative and hypnotic drug that is a member of the long-acting benzodiazepines family with active hepatic metabolites. Diazepam is prescribed to relieve anxiety, sleep disorders, and panic disorders. It is also used as an anticonvulsant and skeletal muscle relaxant, treatment of muscle contraction, and seizures. ${ }^{113}$ It is recommended for anxiety, alcohol withdrawal syndrome, seizure disorders, myoclonic epilepsy, treatment of panic and excessive fear, skeletal muscle spasm, headache, and involuntary shaking or tremors. The diazepam-associated complications include mental retardation, drowsiness, slurred speech, bradycardia, shortness of breath, imbalance, skin rash, sore throat, fever and shivering, and abnormal bruising or bleeding, sores inside the mouth, Jaundice, memory loss, nausea, anxiety or irritability. ${ }^{114}$

\section{Clonazepam}

Clonazepam is a benzodiazepine drug prescribed to treat various types of epilepsy and seizures in children and adults. Clonazepam controls seizures by reducing abnormal electrical activity in the brain. There are different types of seizures, depending on which cells in the brain are electrically disturbed. Symptoms that occur during a seizure can affect the muscles, senses, mood, emotions, concentration, alertness, or a combination of them. Therefore, in the treatment of epilepsy, prevention, and reduction of the number of times, seizures are the main target. Clonazepam controls the electrical activity of brain cells by controlling the symptoms of seizures and prevents seizures. It also helps reduce the severity of seizures by relaxing the muscles that contract during a seizure. ${ }^{115}$ Common adverse events of clonazepam include drowsiness, weakness, and dizziness. Concentration problems, abnormal eye movements, and forgetfulness can also occur with this medication, which you can discuss with your doctor. In children, increased salivation may cause coughing or discomfort. ${ }^{116}$

\section{Phenobarbital}

Phenobarbital is one of the oldest drugs used to treat epilepsy, discovered in 1912. It is inexpensive and effective in treating most types of epilepsy, but in recent years, control has been used because of its adverse events. Initially, phenobarbital was used as a sleeping pill. ${ }^{117}$ Therefore, it is not surprising that patients taking this drug become drowsy, although this drowsiness usually decreases over time. Conversely, in children, phenobarbital may cause them to become more active and even more aggressive. In a small number of people, phenobarbital may cause redness of the skin and blisters. Taking large amounts of this drug can cause drowsiness, impotence, depression, and poor memory. Long-term phenobarbital use can reduce the body's storage of vitamin D and folic acid. $^{118}$

\section{Primidone}

Primidone is used as a non-specific CNS depressant alone or in combination with other anticonvulsant drugs to control seizures of large refractory epilepsy and to treat focal or psychomotor seizures. The drug's mechanism of action is unknown. Part of the drug's activity may be due to phenobarbital (its active metabolite). ${ }^{119}$ Adverse primidone events include drowsiness, imbalance, nausea, nystagmus, visual disturbances, and skin rashes occur, especially at the beginning of treatment, and are usually reversible with continued treatment. Other adverse events of the drug include depression, mobility, restlessness, disturbed consciousness in the elderly, excessive and abnormal excitement and activity in children, and megaloblastic anemia. $^{120}$

\section{Pregabalin}

Known as (CI-1008,3-isobutyl- $\gamma$-aminobutyric acid) was approved for the treatment of epileptic disorders, and targeting the calcium channel $(\alpha 2-\delta){ }^{121}$

\section{Vigabatrin}

This transaminase GABA prohibits neuronal uptake of GABA, with release into the synapse. ${ }^{122}$

\section{Carisbamate}

It was accepted in 2008 as a new drug application to the United State Food and Drug Administration (FDA). It is metabolized by glucuronidation and aliphatic side-chain oxidation. ${ }^{123}$ François et al conducted a study to observe the effect of this drug in an animal 
model of GTCS and reported that this drug has a superior effect on primary generalized seizures of tonic-clonic type. ${ }^{124}$

\section{Eslicarbazepine Acetate (ESL)}

Compound with anticonvulsant activity [(S)-(-)-10acetoxy-10, 11-dihydro-5H-dibenz [b, f] azepine-5-carboxamide], a novel central nervous system (CNS)-active agent. Patients with epilepsy showed favorable response after taking this medication. ${ }^{125}$ Carreño et al, in three Phase III trials, investigated whether eslicarbazepine acetate could lead to exacerbation of seizures in patients with epilepsy or not and showed that treatment with this adjunctive does not appear to aggravate GTCS. ${ }^{126}$ In a prospective, non-interventional study on epileptic patients in 17 hospitals, demonstrated the efficacy and tolerability of eslicarbazepine acetate and reported its frequent use as monotherapy lack of severe adverse effects. $^{127}$

\section{Lacosamide}

This medication has been approved to administer in patients aged four and older. This non-enzyme-inducing drug is indicated for monotherapy in focal epilepsies. ${ }^{128}$ Vossler et al conducted a Phase 3, double-blind, randomised -controlled trial to evaluate the efficacy and safety of lacosamide in patients with uncontrolled GTCS and claimed that it is an effective and generally safe treatment for uncontrolled generalized seizures of tonic-clonic type. ${ }^{129}$ Schmitz et al, in a hoc analysis of a double-blind non-inferiority monotherapy trial (NCT01243177) of patients with GTCS who were received either lacosamide or carbamazepine controlled-release (carbamazepine-CR), showed that lacosamide is an effective and generally well tolerated than carbamazepine-CR. ${ }^{130}$ Gathering empirical evidence from both in vivo and in vitro studies suggests that some antiarrhythmic drugs, such as dronedarone, not only played an important role in initiating seizures but also increases the anticonvulsant potency of classical AEDs. Clinical evidence shows that the combination of dronedarone with lacosamide should be neutral from a clinical viewpoint, and a special attention is recommended for patients with GTCS because of some adverse-effects. ${ }^{131}$ In a clinical study, Abarrategui et al assessed the effect of lacosamide on refractory epilepsy and suggested that lacosamide can be a reasonable option for patients with this type of epilepsy. ${ }^{132}$

\section{AEDs Monotherapy or Combination Therapy}

So far, the clinical development trend of old and new AEDs revealed that old AEDs entered the market without any precise randomized clinical trials (RCTs) and were used simultaneously in both monotherapy and combination therapy. After years of clinical experience, monotherapy was considered the preferred treatment for newly diagnosed epilepsy, especially the drug-resistant form, followed by comparative monotherapy trials of conventional AEDs. Hence, the new AEDs were introduced after accurate RCTs of adjuvant therapy, indicating that the new AEDs were superior to placebo in adjuvant therapy. Thus, the new AEDs, after years of use in combination therapy, underwent comparative monotherapy RCTs to promote themselves as first-line drugs for patients with epilepsy, of which some were acknowledged as the drugs of choice in several specific epilepsy syndromes (Table 3).

\section{Challenges in Epilepsy Treatment During Pregnancy}

Seizure-associated diseases such as epilepsy affect approximately $0.5 \%$ to $1 \%$ of the general population and pregnant women. Most women with epilepsy have an accident-free pregnancy. The effect of pregnancy on the frequency of epileptic attacks can be variable. According to various sources, $15 \%$ to $50 \%$ of patients have an increase in seizure frequency during pregnancy, and a decrease in seizure frequency occurs in approximately $25 \%$ of patients, while a significant percentage of women do not experience a change in seizure frequency during pregnancy. ${ }^{133}$ In a systematic review study of 59 studies performed on 65,533 pregnant women with epilepsy, in $24 \%$ of patients, an increase in the frequency of attacks, in $23 \%$ of patients a decrease in the frequency of attacks, and in $53 \%$ of patients no change in the frequency of attacks was observed. ${ }^{134}$ The patient's age, type of seizure, AEDs regimen, or frequency of seizures in the prenatal period cannot predict possible seizure frequency changes for a pregnant woman. ${ }^{135}$

\section{The Effect of Endo-Cannabinoids Inhibitors}

In recent years, many efforts have been made to find new treatments for epilepsy. Anandamides and diarchidonyl glycerol are two main and important ligands of the endocannabinoid system, of which each produced and deleted 


\begin{tabular}{|c|c|c|c|c|c|c|c|c|c|}
\hline 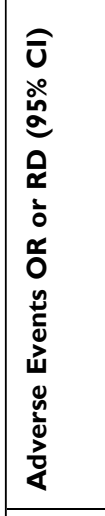 & 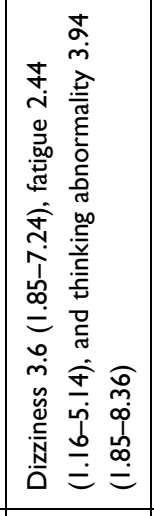 & 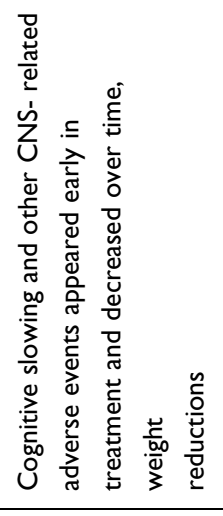 & 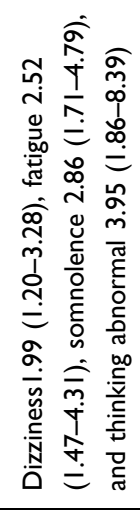 & | & 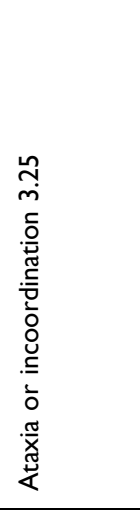 & 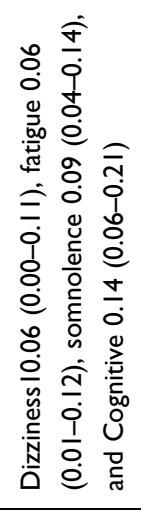 & & 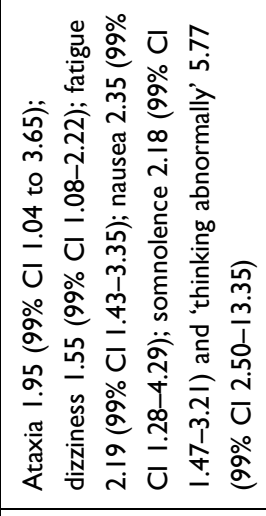 & \\
\hline 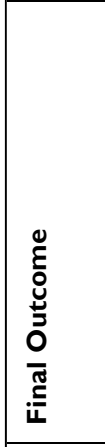 & 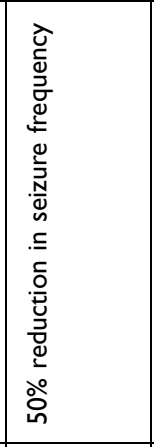 & 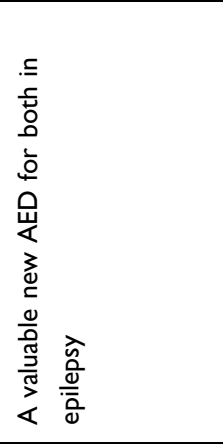 & 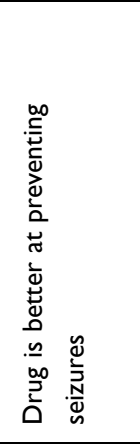 & 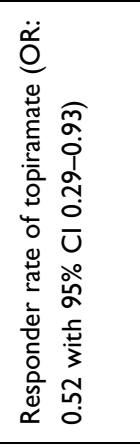 & 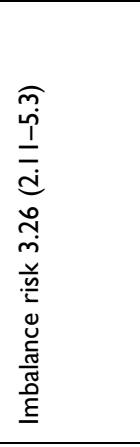 & 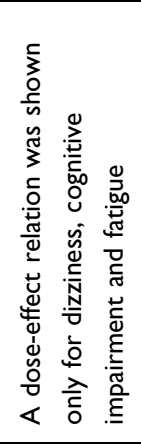 & 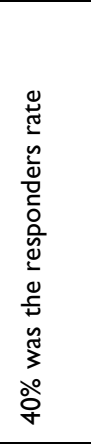 & 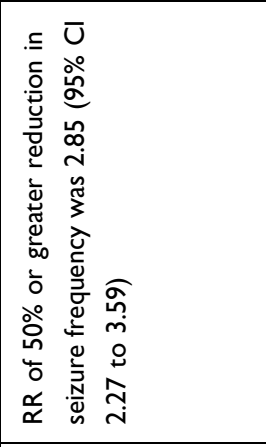 & 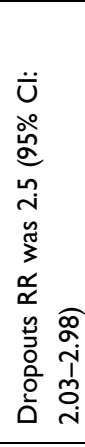 \\
\hline 窟离 & $\underset{\mathscr{U}}{\breve{L}}$ & $\underset{\check{U}}{\tilde{y}}$ & $\underset{\check{U}}{\breve{u}}$ & $\underset{\check{U}}{\tilde{y}}$ & $\underset{\check{u}}{\tilde{u}}$ & 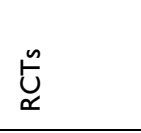 & 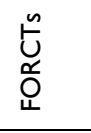 & $\underset{\check{U}}{\breve{u}}$ & $\underset{\check{U}}{\breve{u}}$ \\
\hline 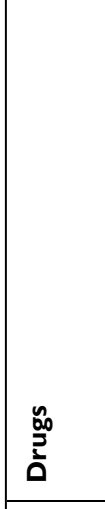 & 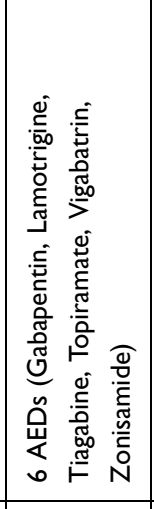 & 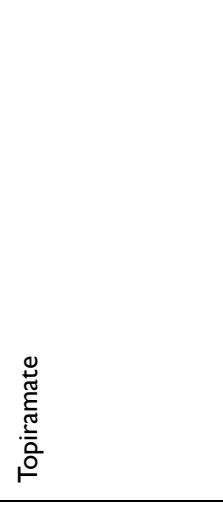 & 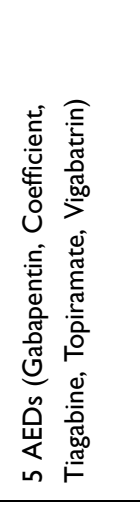 & 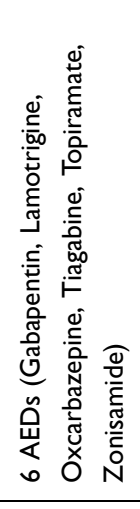 & 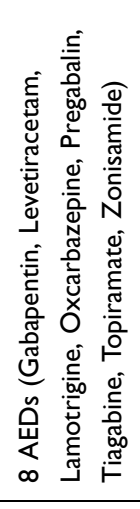 & 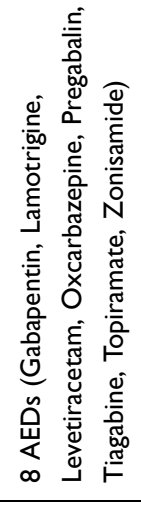 & 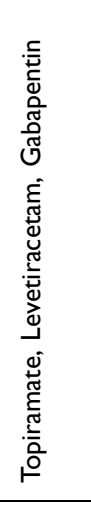 & 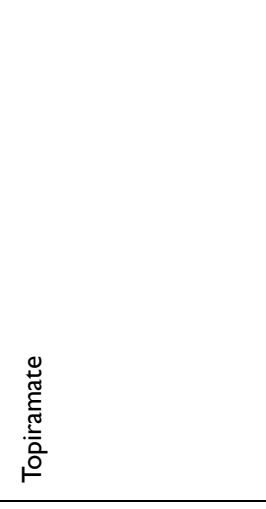 & 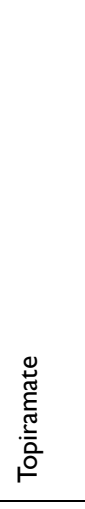 \\
\hline 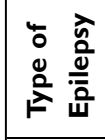 & щuㅁ & 山्ㅁ & $\underset{\propto}{\breve{~}}$ & $\underset{\propto}{\breve{~}}$ & 뜸 & 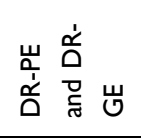 & $\underset{\propto}{\breve{~}}$ & 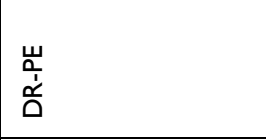 & 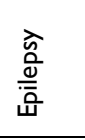 \\
\hline 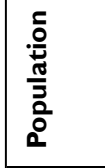 & în & $\frac{\nabla}{N}$ & হ্ণি & 웜 & $\underset{\Im}{\stackrel{\Im}{\gamma}}$ & $\stackrel{\tilde{o}}{\dot{q}}$ & $\hat{i n}$ & $\frac{\mathfrak{m}}{\underline{m}}$ & $\stackrel{\widetilde{N}}{\underline{\underline{N}}}$ \\
\hline 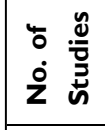 & in & in & సి & $\sigma$ & $\simeq$ & $\stackrel{\sim}{m}$ & 으 & 으 & $\sigma$ \\
\hline 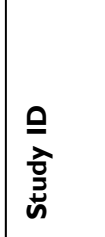 & 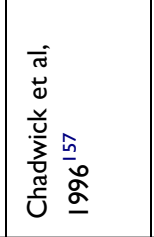 & 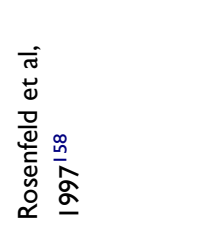 & 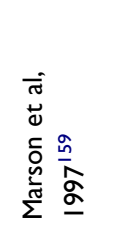 & 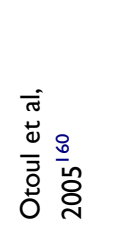 & 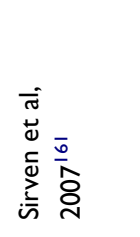 & 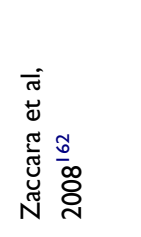 & 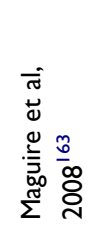 & 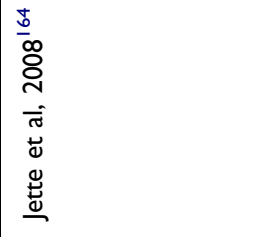 & 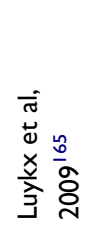 \\
\hline
\end{tabular}




\begin{tabular}{|c|c|c|c|c|c|c|c|}
\hline 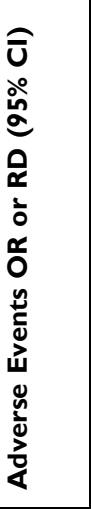 & & 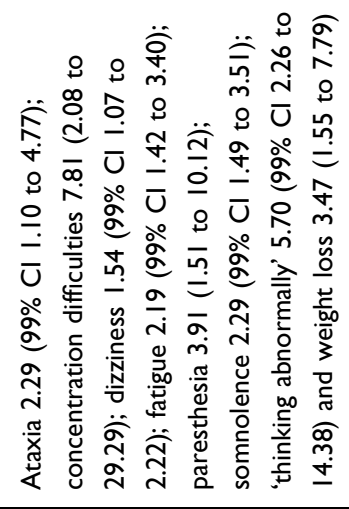 & 1 & 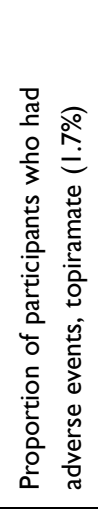 & 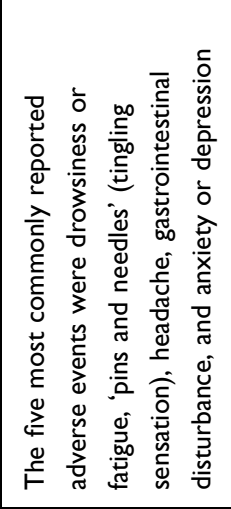 & 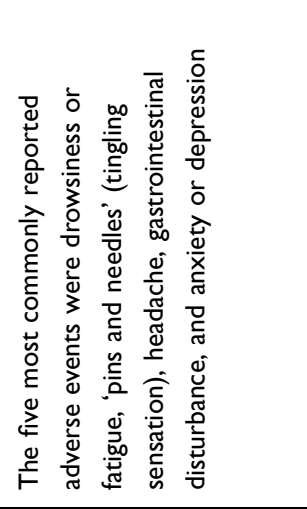 & 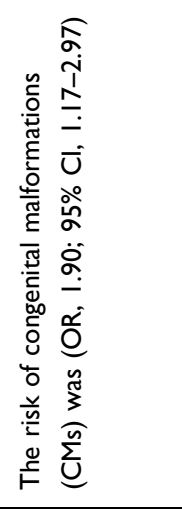 \\
\hline 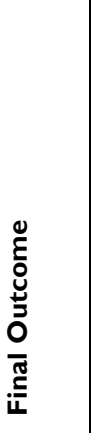 & 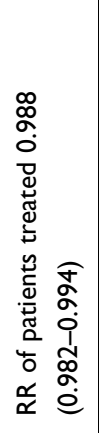 & 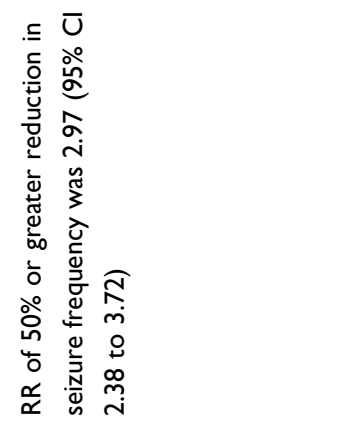 & 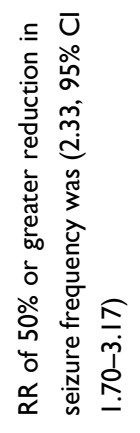 & 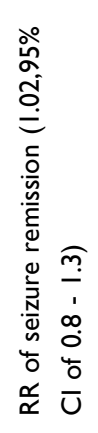 & 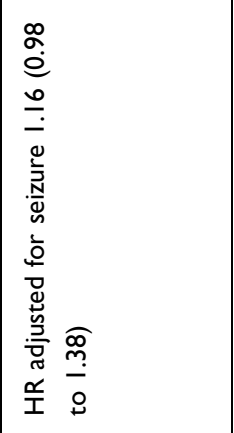 & 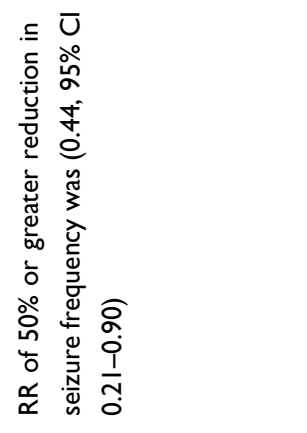 & 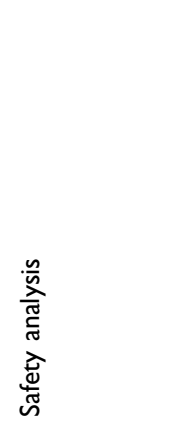 \\
\hline 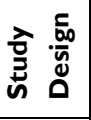 & $\underset{\mathscr{U}}{\breve{U}}$ & 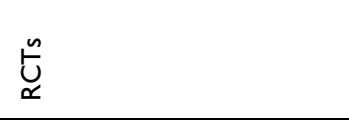 & $\underset{\longleftarrow}{\breve{u}}$ & $\underset{\check{U}}{\breve{c}}$ & $\underset{\mathscr{U}}{\mathscr{L}}$ & $\underset{\check{U}}{\breve{\varrho}}$ & 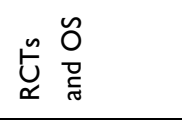 \\
\hline 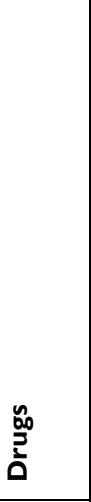 & 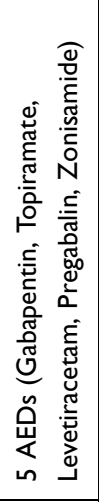 & 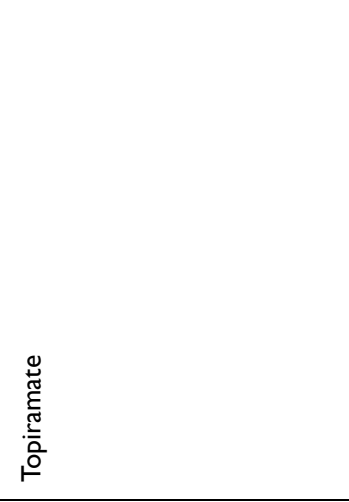 & 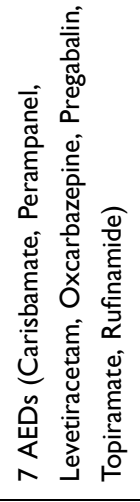 & 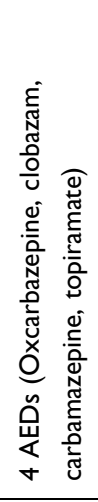 & 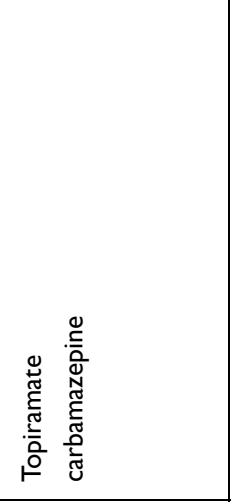 & 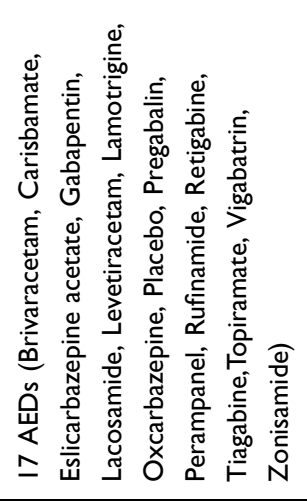 & 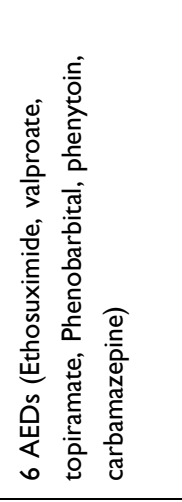 \\
\hline 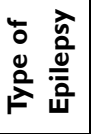 & щ山ㅁ & 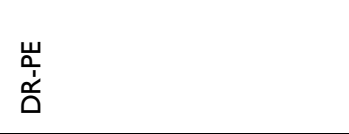 & $\underset{\propto}{\breve{~}}$ & 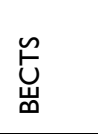 & щuㅁ & щᄄ口 & 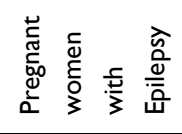 \\
\hline 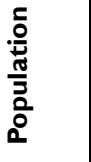 & $\begin{array}{l}\stackrel{m}{\sim} \\
\text { }\end{array}$ & 京 & 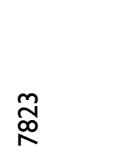 & ָั & $\underline{\underline{\underline{n}}}$ & $\stackrel{\stackrel{\infty}{\circledR}}{\simeq}$ & $\begin{array}{l}\overline{5} \\
\substack{0 \\
\infty}\end{array}$ \\
\hline 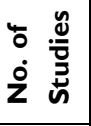 & $\stackrel{m}{m}$ & $=$ & $\stackrel{ \pm}{\sim}$ & $\nabla$ & $\underline{m}$ & $\underline{m}$ & 2 \\
\hline 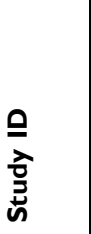 & 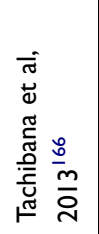 & 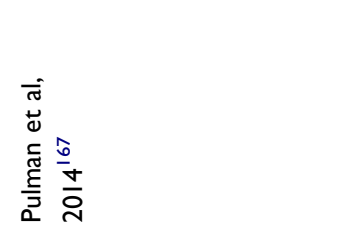 & 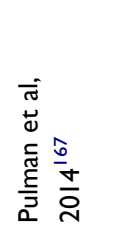 & 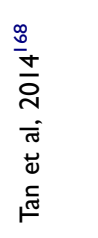 & $\begin{array}{l}\frac{0}{\pi} \\
\stackrel{0}{0} \\
\frac{c}{c} \\
\frac{0}{0} \\
z \\
z\end{array}$ & 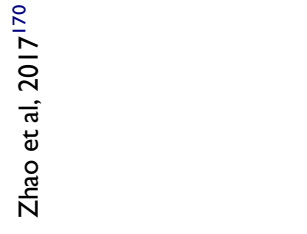 & 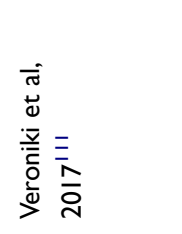 \\
\hline
\end{tabular}




\begin{tabular}{|c|c|c|c|c|c|c|}
\hline 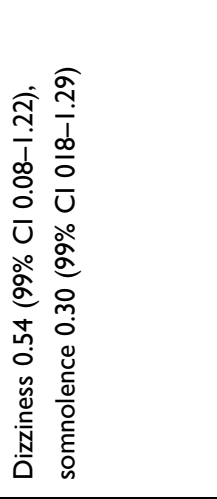 & 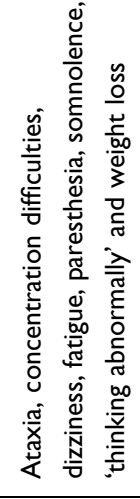 & 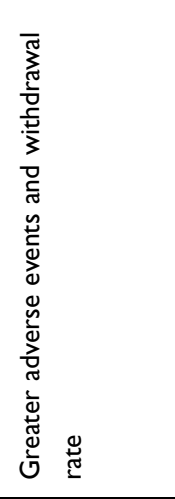 & 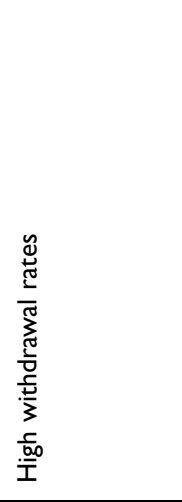 & 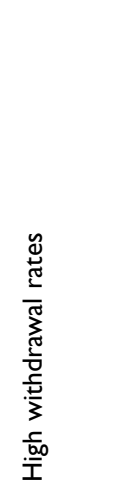 & 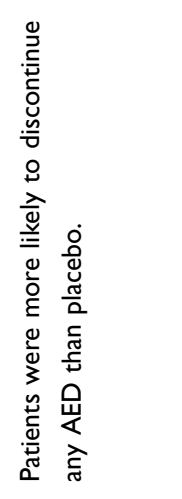 & 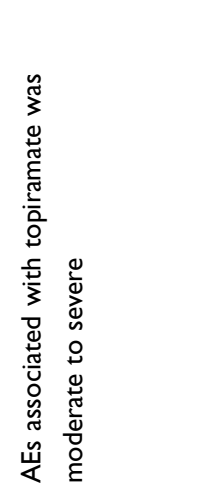 \\
\hline 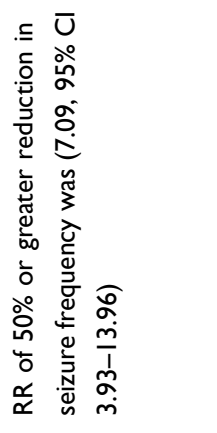 & 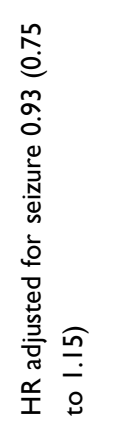 & 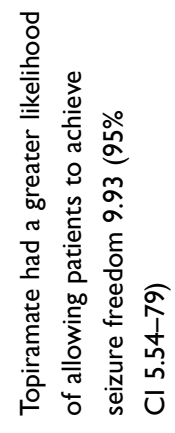 & 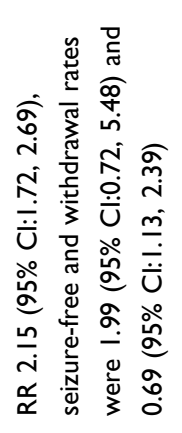 & 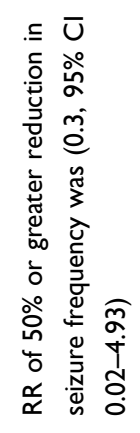 & 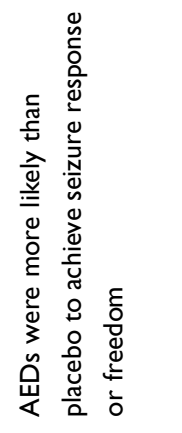 & 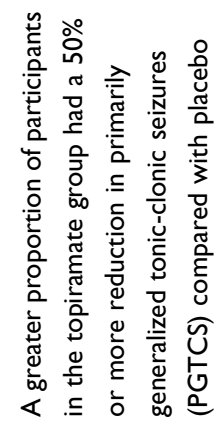 \\
\hline$\underset{\check{U}}{\breve{u}}$ & 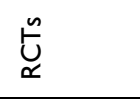 & $\underset{\mathscr{u}}{\breve{u}}$ & 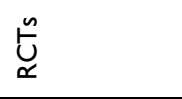 & $\underset{\check{U}}{\breve{u}}$ & $\underset{\mathscr{U}}{\tilde{U}}$ & $\underset{\mathscr{U}}{\stackrel{n}{U}}$ \\
\hline 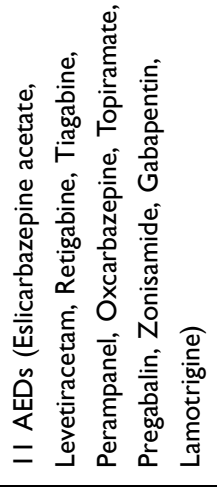 & 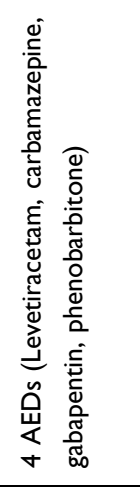 & 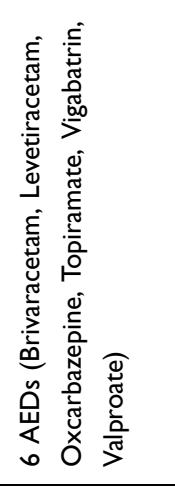 & 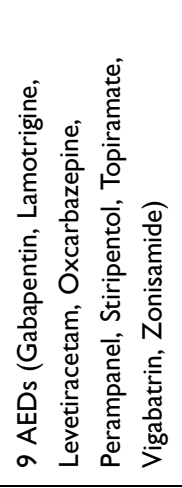 & 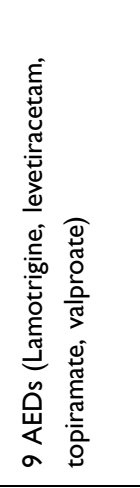 & 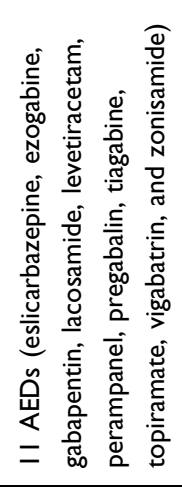 & 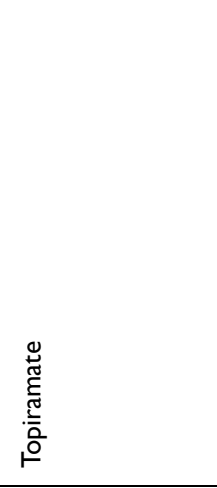 \\
\hline$\underset{\propto}{\ddot{\alpha}}$ & 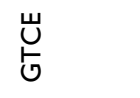 & $\ddot{\ltimes}$ & 山् & 惢 & $\underset{\propto}{\breve{~}}$ & $\underline{\underline{\Sigma}}$ \\
\hline 总 & 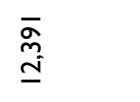 & $\begin{array}{l}\overline{\bar{N}} \\
\text { مे }\end{array}$ & $\begin{array}{l}\widehat{\infty} \\
\stackrel{\infty}{2}\end{array}$ & 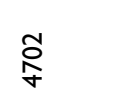 & $\begin{array}{l}\text { జ } \\
\text { L }\end{array}$ & œ \\
\hline$\tilde{m}$ & N & $\stackrel{\circ}{\circ}$ & $\simeq$ & $\underline{0}$ & নి & $m$ \\
\hline 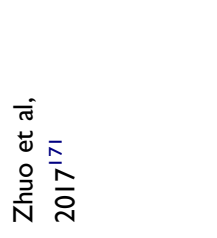 & 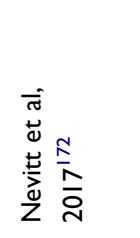 & 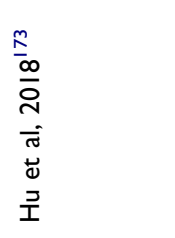 & 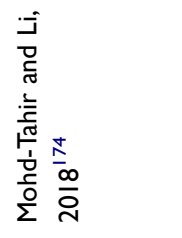 & 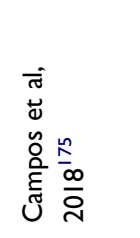 & 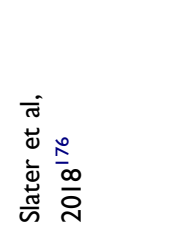 & 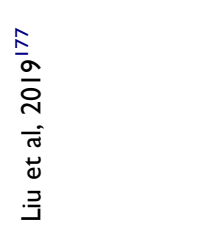 \\
\hline
\end{tabular}




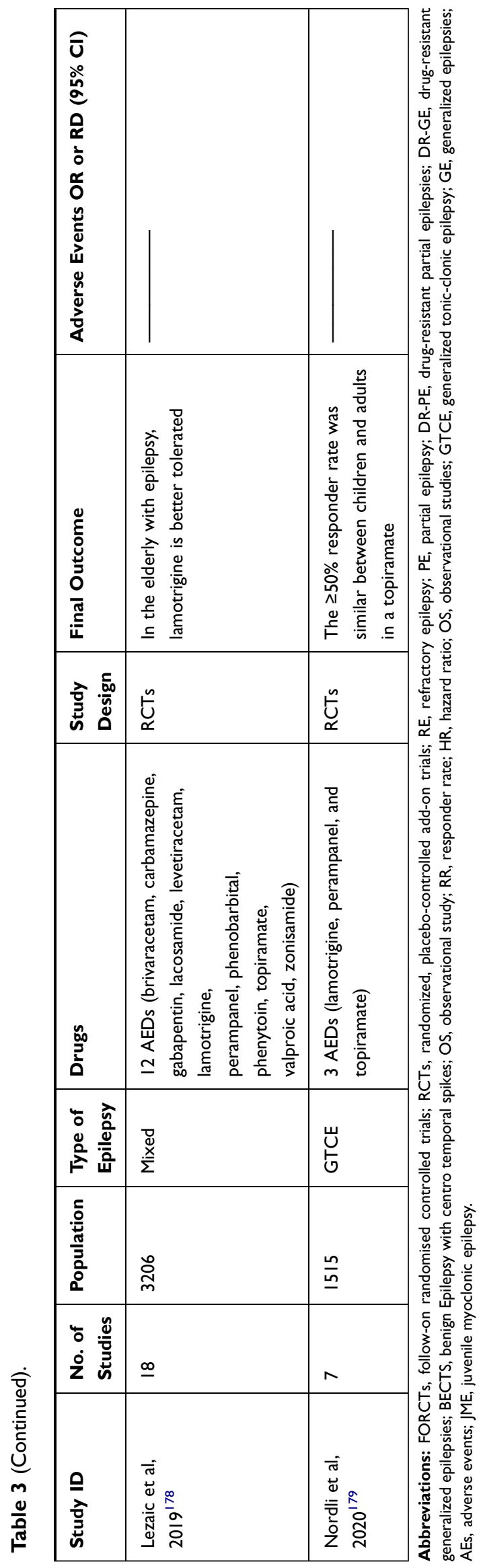

through specific enzyme pathways. ${ }^{136,137}$ The presence of these compounds in the neuronal environment and at the site of synaptic communication can cause modulatory effects on these cells' properties and performance. ${ }^{138,139}$ Most anandamides are produced by N-acylphosphatidylethanolamine-phospholipase D (NAPE-PLD) enzymes inside the cell and then transported to the extracellular space. The fatty-acid amide hydrolase (FAAH) enzyme is responsible for metabolizing and removing accumulated anandamides. ${ }^{140}$ Considering the abundance and importance of these two endo-cannabinoid ligands and the main pathways mentioned in their synthesis and removal, it seems that by pharmacological manipulation in these pathways, the level of these two main ligands in the brain can be changed. In a study, the use of monoacylglycerol lipase (MAGL) enzyme inhibitor, which is involved in the breakdown of 2-arachidonoylglycerol (2-AG), increased seizure frequency; ${ }^{141}$ while, in another study, the use of the alpha-beta hydrolase domain (ABHD) enzyme inhibitor, which is also involved in the breakdown of 2-AG, improved seizure rates. ${ }^{142}$ The results of a study showed that systemic injection of both enzymes involved in 2-AG deletion can significantly reduce the seizure, and the time delay in reaching stages 4 and 5 of seizures increased significantly. In addition, the incidence of stage 5 of seizure and the percentage of deaths due to seizures were significantly reduced by this injection. ${ }^{143}$ Recent studies have shown the effectiveness of plant cannabinoids in controlling the occurrence of epileptic seizures in laboratory models. ${ }^{144-146}$ In a study, systemic application of a herbal cannabinoid in two pilocarpine-induced seizure models and a penicillin-induced seizure model significantly reduced the incidence of stages 4 and 5 of epilepsy. ${ }^{147}$ In another study on the seizure model, laboratory-produced phytocannabinoid compounds significantly reduced the severity of seizures and post-seizure mortality. ${ }^{148}$

\section{Ongoing Trials}

The search terms were "treatment," "therapy" OR "Drug" OR "antiepileptic drugs" OR "AEDs" AND "generalized tonic-clonic seizure" OR "Epilepsy" on ClinicalTrials.gov and ICTRP search portal and resulted in 187 active trials, with 42 trials specific to epilepsy as of September 23, 2020. Of these 187 trials, approximately 42 trials (including those not yet recruiting, recruiting, active, or completed) included pharmacological therapy to treat epilepsy in adult patients (Table 4). Of these 42 trials, 37 are interventional studies, 


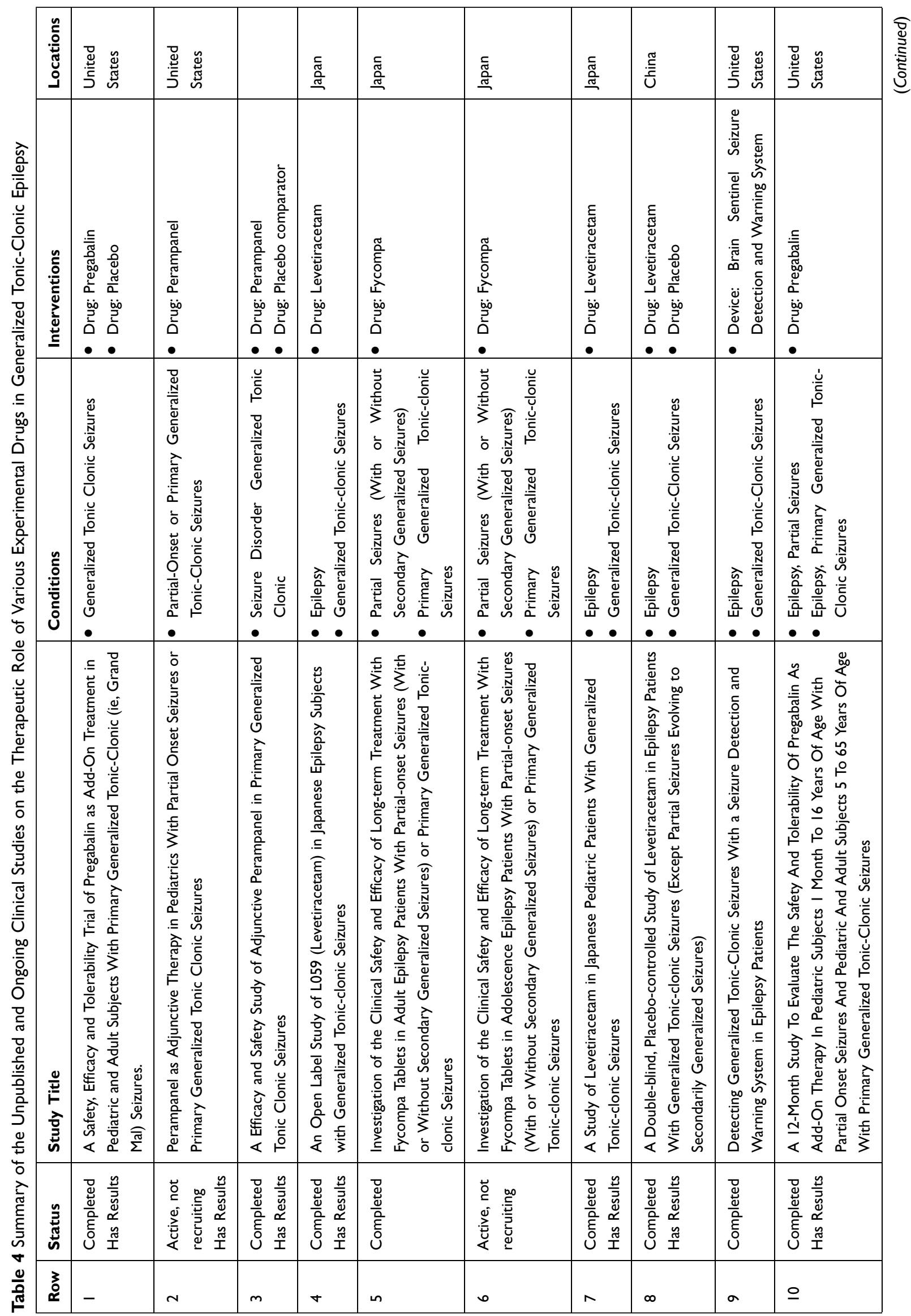




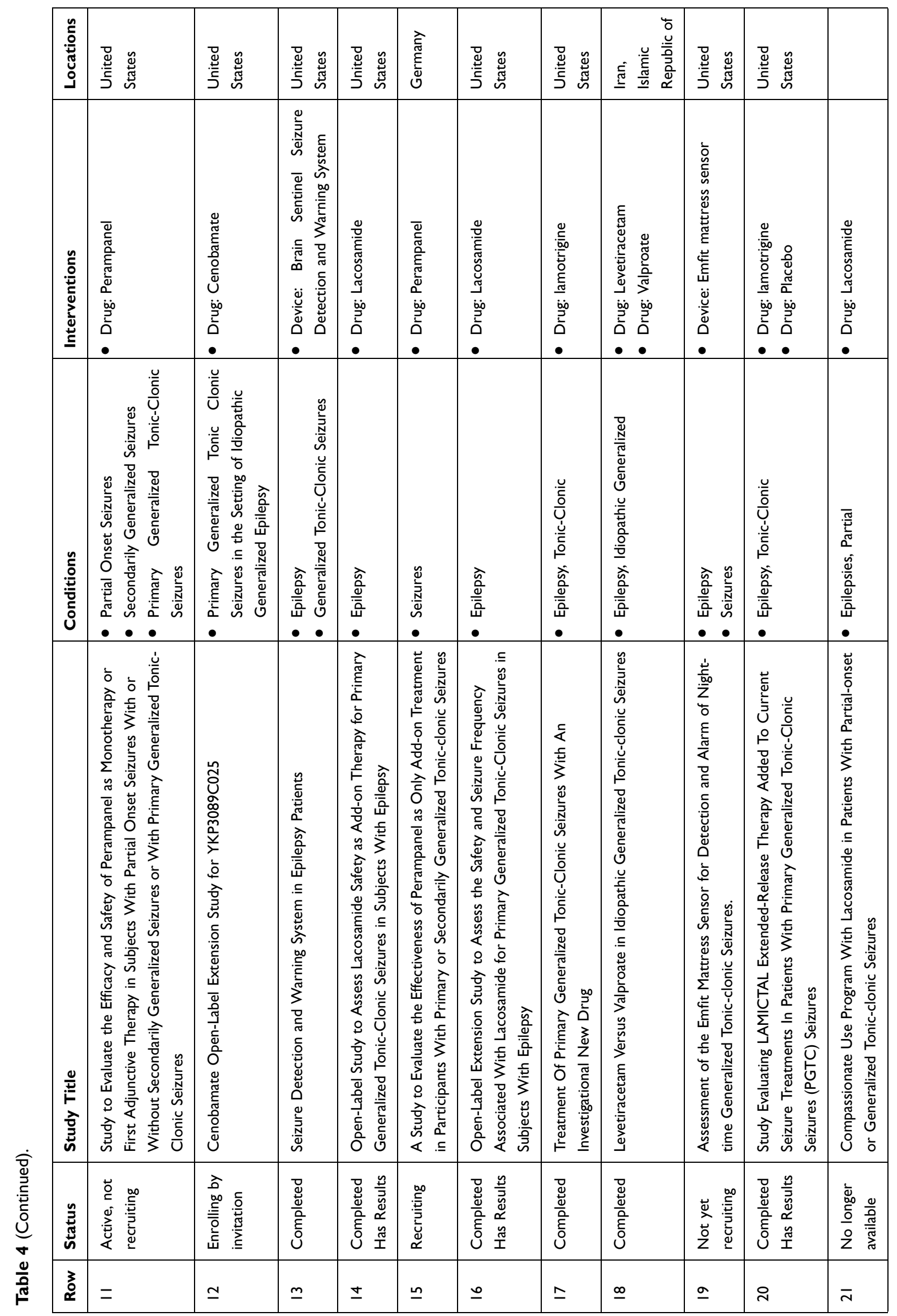




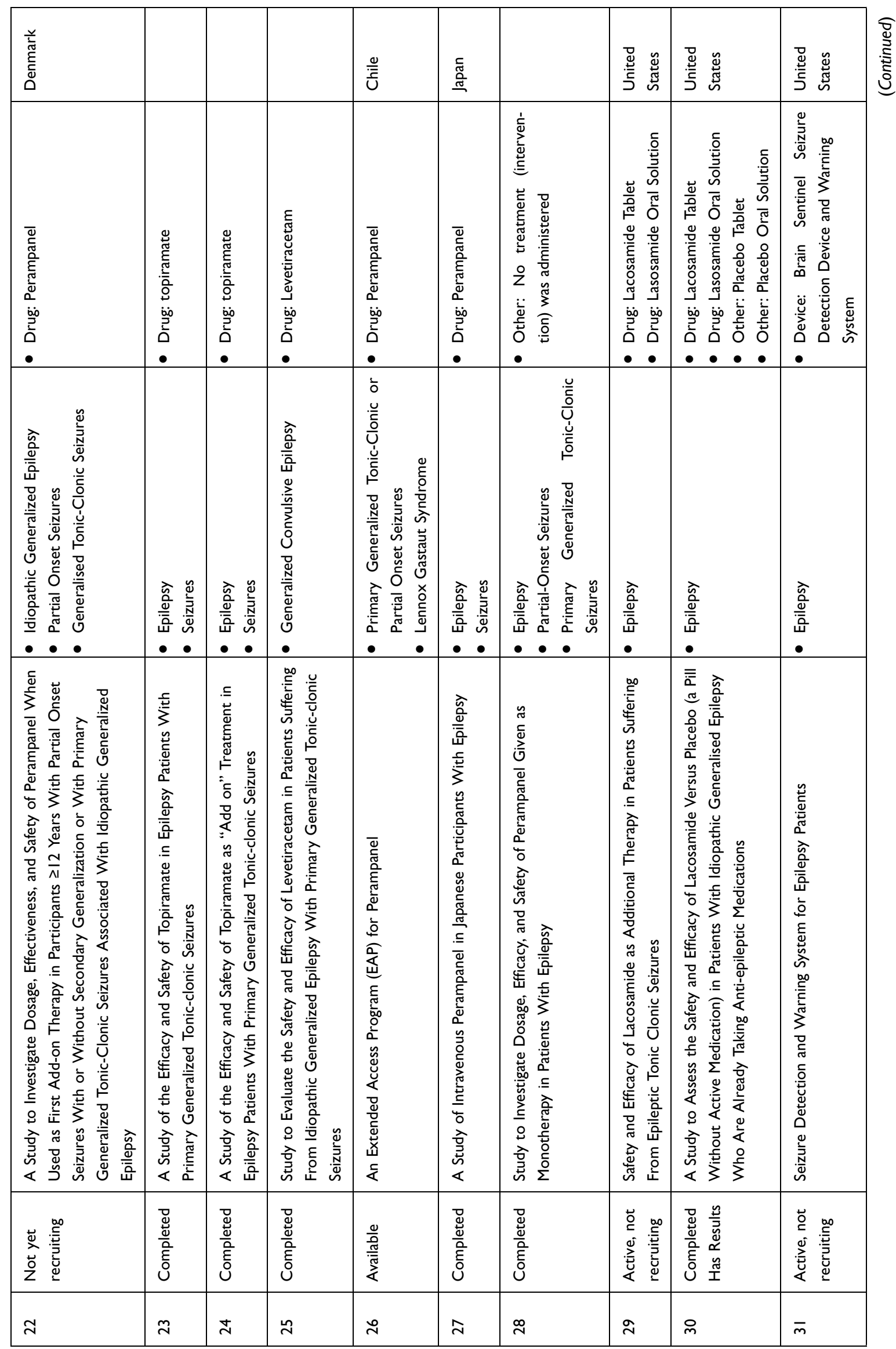




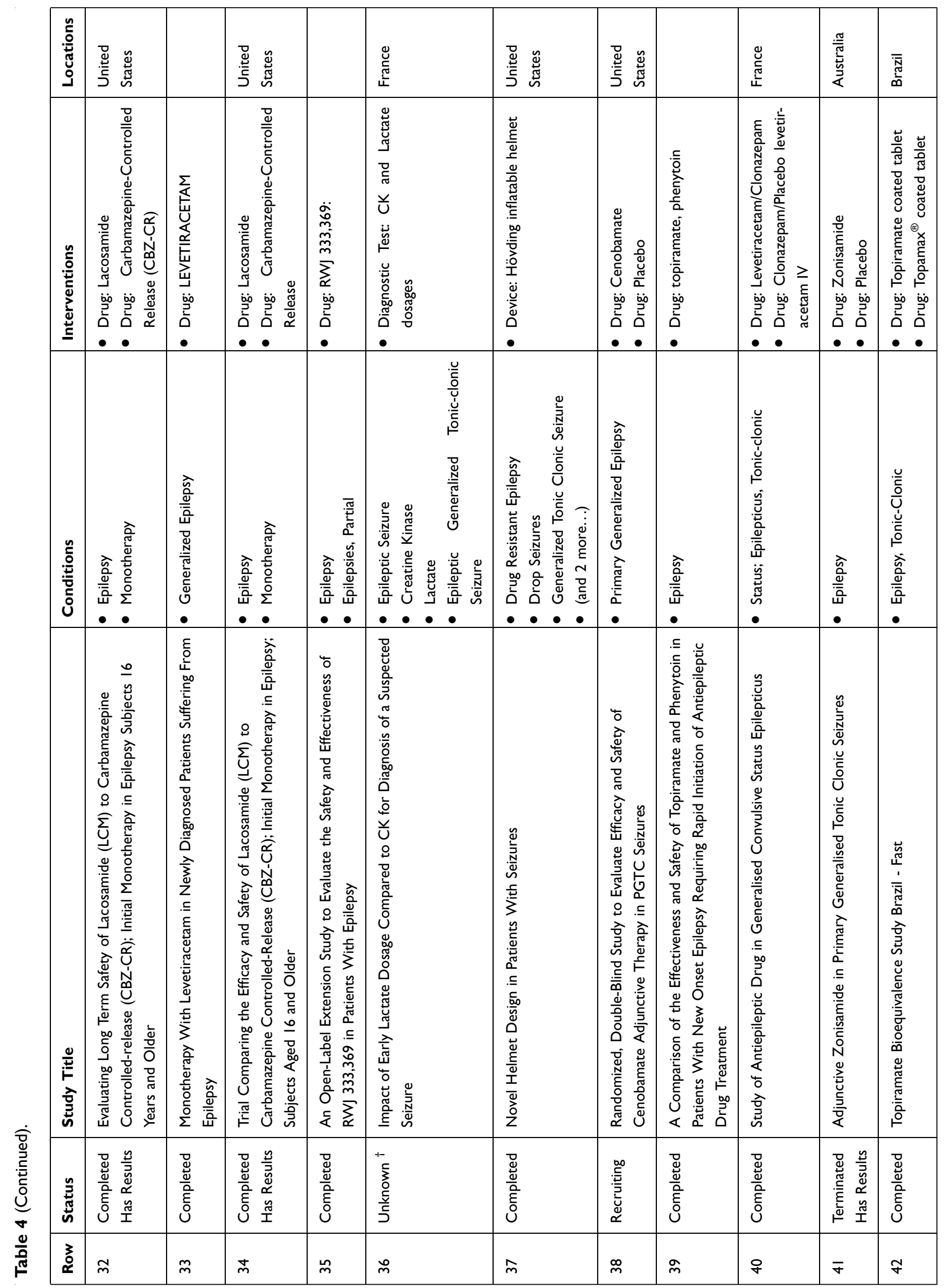


with 29 placebo-controlled trials, and 5 were about using devices such as Hövding inflatable helmet and Brain Sentinel Seizure Detection Device and Warning System (BSSDDWS). Per description of the studies, there are 7 Phase IV, 26 Phase III, 5 Phase II, and 4 Phase I trials.

\section{Limitations}

This review has several limitations to note. First, the published evidence is derived solely from observational studies or small-size clinical trials (less than 250 patients), which may introduce high risks of bias or imprecision about the treatment effect. Second, our review focused on a wide range of patient's age, and the data may not be applicable to specific age group populations. Fourth, the articles were published in English-language or translations, so relevant international data could be lacking.

\section{Conclusions}

The primary goal in using experimental therapeutic drug strategies in patients with epilepsy is to prevent recurrent seizures and reduce the rate of traumatic events that may occur during seizures. With the right AEDs treatment regimen, about $70 \%$ of people with epilepsy do not experience the seizures again. However, about one-third of people with epilepsy still has seizures despite taking several AEDs. Continued seizures put patients at risk for SUDEP and may be associated with depression and lower quality of life. Strategies to try to prevent SUDEP include reducing the rate of seizures (by considering epilepsy surgery or lifestyle changes), monitoring heart and respiratory problems during and after seizures, monitoring patients at night, or using pillows to prevent respiratory problems. Drugs that increase the brain chemical serotonin and decrease the brain chemicals adenosine and opioids may also help prevent respiratory problems.

We can also greatly reduce these people's learning disabilities, especially in school-age, through the prevention of recurrent seizures and disruptions in daily activities. So far, various drug treatments have been offered for patients with epilepsy, which have been classified according to the type of epilepsy, the effectiveness of the drugs and adverse events. Drugs such as levetiracetam, valproic acid, and lamotrigine are at the forefront of these patients' treatment. In resistant form of epilepsy, neuro-stimulation by intra-cerebral electrodes has also been suggested. The variety and sample size of clinical trials launched to investigate potential therapies for epilepsy highlight both the need and capability to produce high-quality evidence. However, it should be noted that some of these patients still do not respond to existing treatments; therefore, it seems that we should look for more specific drugs that have fewer adverse events and have a greater effect in stopping seizures.

\section{Disclosure}

The authors report no conflicts of interest in this work.

\section{References}

1. Sirven JI. Epilepsy: a spectrum disorder. Cold Spring Harb Perspect Med. 2015;5(9):a022848-a022848. doi:10.1101/cshperspect.a022848

2. Zewudie A, Mamo Y, Feyissa D, Yimam M, Mekonen G, Abdela A. Epilepsy treatment outcome and its predictors among ambulatory patients with epilepsy at Mizan-Tepi University teaching hospital, Southwest Ethiopia. Neurol Res Int. 2020;2020:8109858. doi:10.1155/2020/8109858

3. Guerreiro CA. Epilepsy: is there hope? Indian $J$ Med Res. 2016;144(5):657-660. doi:10.4103/ijmr.IJMR_1051_16

4. Saetre E, Abdelnoor M. Incidence rate of sudden death in epilepsy: a systematic review and meta-analysis. Epilepsy Behav. 2018;86:193-199. doi:10.1016/j.yebeh.2018.06.037

5. Feigin VL, Vos T, Alahdab F, et al. Burden of neurological disorders across the US from 1990-2017: a global burden of disease study. JAMA Neurol. 2020.

6. Deuschl G, Beghi E, Fazekas F, et al. The burden of neurological diseases in Europe: an analysis for the global burden of disease study 2017. Lancet Public Health. 2020;5(10):e551-e567.

7. Beghi E. The epidemiology of epilepsy. Neuroepidemiology. 2020;54(2):185-191. doi:10.1159/000503831

8. Camfield P, Camfield C. Incidence, prevalence and aetiology of seizures and epilepsy in children. Epileptic Disord. 2015;17:117-123.

9. Gabrielli L, Bonasoni P, Santini D, et al. Congenital cytomegalovirus infection: patterns of fetal brain damage. Clin Microbiol Infect. 2012;18:E419-E427. doi:10.1111/j.1469-0691.2012.03983.x

10. Beghi E, Giussani G. Aging and the epidemiology of epilepsy. Neuroepidemiology. 2018;51(3-4):216-223. doi:10.1159/000493484

11. Birbeck GL. Epilepsy care in developing countries: part I of II. Epilepsy Curr. 2010;10(4):75-79. doi:10.1111/j.1535-7511.2010. 01362.x

12. Gilliam F, Hecimovic H, Sheline Y. Psychiatric comorbidity, health, and function in epilepsy. Epilepsy Behav. 2004;4(Suppl 4):S26-30. doi:10.1016/j.yebeh.2003.10.003

13. Noebels J. Pathway-driven discovery of epilepsy genes. Nat Neurosci. 2015;18(3):344-350. doi:10.1038/nn.3933

14. McKee AC, Daneshvar DH. The neuropathology of traumatic brain injury. Handb Clin Neurol. 2015;127:45-66.

15. Yu C, Zhou D, Jiang W, Mu J. Current epidemiological and etiological characteristics and treatment of seizures or epilepsy in patients with HIV infection. Acta Epileptologica. 2020;2(1):18. doi:10.1186/s42494-020-00028-8

16. Zhang P, Yang Y, Zou J, Yang X, Liu Q, Chen Y. Seizures and epilepsy secondary to viral infection in the central nervous system. Acta Epileptologica. 2020;2(1):12. doi:10.1186/s42494020-00022-0

17. Nalivaeva NN, Turner AJ, Zhuravin IA. Role of prenatal hypoxia in brain development, cognitive functions, and neurodegeneration. Front Neurosci. 2018;12:825.

18. Wong M. The role of glia in epilepsy, intellectual disability, and other neurodevelopmental disorders in tuberous sclerosis complex. J Neurodev Disord. 2019;11(1):30. doi:10.1186/s1168 9-019-9289-6 
19. Barone V, van Putten M, Visser GH. Absence epilepsy: characteristics, pathophysiology, attention impairments, and the related risk of accidents. A narrative review. Epilepsy Behav. 2020; 112:107342. doi:10.1016/j.yebeh.2020.107342

20. Barker-Haliski M, White HS. Glutamatergic mechanisms associated with seizures and epilepsy. Cold Spring Harb Perspect Med. 2015;5(8):a022863. doi:10.1101/cshperspect.a022863

21. Galanopoulou AS. GABA(A) receptors in normal development and seizures: friends or foes? Curr Neuropharmacol. 2008;6 (1):1-20. doi:10.2174/157015908783769653

22. Treiman DM. GABAergic mechanisms in epilepsy. Epilepsia. 2001;42(Suppl 3):8-12. doi:10.1046/j.1528-1157.2001.042suppl. 3008.x

23. Stafstrom CE. The pathophysiology of epileptic seizures: a primer for pediatricians. Pediatr Rev. 1998;19(10):342-351. doi:10.1542/ pir.19-10-342

24. Nass RD, Sassen R, Elger CE, Surges R. The role of postictal laboratory blood analyses in the diagnosis and prognosis of seizures. Seizure. 2017;47:51-65.

25. Lahat E, Eshel G, Heyman E, Bar J, Katz Y, Aladjem M. Elevated serum creatine kinase. Following febrile seizures. Clin Pediatr (Phila). 1989;28(10):449-451. doi:10.1177/000992288902801003

26. Brigo F, Igwe SC, Erro R, et al. Postictal serum creatine kinase for the differential diagnosis of epileptic seizures and psychogenic non-epileptic seizures: a systematic review. J Neurol. 2015;262 (2):251-257. doi:10.1007/s00415-014-7369-9

27. Nass RD, Meiling S, Andrié RP, Elger CE, Surges R. Laboratory markers of cardiac and metabolic complications after generalized tonic-clonic seizures. BMC Neurol. 2017;17(1):187. doi:10.1186/ s12883-017-0965-4

28. Dafotakis M, Heckelmann J, Zechbauer S, et al. [Laboratory diagnostics in transient loss of consciousness: serum lactate compared to serum creatine kinase as diagnostic indicator for generalized tonic-clonic seizures]. Der Nervenarzt. 2018;89(8):922-927. German. doi:10.1007/s00115-018-0505-5

29. Willert C, Spitzer C, Kusserow S, Runge U. Serum neuron-specific enolase, prolactin, and creatine kinase after epileptic and psychogenic non-epileptic seizures. Acta Neurol Scand. 2004;109(5):318-323. doi:10.1046/j.1600-0404.2003.00232.x

30. Chen DK, So YT, Fisher RS. Use of serum prolactin in diagnosing epileptic seizures: report of the therapeutics and technology assessment subcommittee of the American academy of neurology. Neurology. 2005;65(5):668-675. doi:10.1212/01.wnl.000017839 1.96957.d0

31. Chowdhury FA, Nashef L, Elwes RD. Misdiagnosis in epilepsy: a review and recognition of diagnostic uncertainty. Eur J Neurol. 2008;15(10):1034-1042. doi:10.1111/j.1468-1331.2008.02260.x

32. Pana R, Labbé A, Dubeau F, Kobayashi E. Evaluation of the "nonepileptic" patient in a tertiary center epilepsy clinic. Epilepsy Behav. 2018;79:100-105. doi:10.1016/j.yebeh.2017.11.001

33. Mannan JB, Wieshmann UC. How accurate are witness descriptions of epileptic seizures? Seizure. 2003;12(7):444-447. doi:10. 1016/S1059-1311(03)00052-9

34. Hines MT. Clinical approach to commonly encountered problems. Equine Internl Med. 2004;111-168. doi:10.1016/B0-72-1697771/50005-6

35. Fedorova ML. [Loss of consciousness in migraine]. Zhurnal Nevropatologii I Psikhiatrii Imeni SS Korsakova. 1978;78 (1):35-41. Russian.

36. Idro R, Marsh K, John CC, Newton CRJ. Cerebral malaria: mechanisms of brain injury and strategies for improved neurocognitive outcome. Pediatr Res. 2010;68(4):267-274. doi:10.12 03/PDR.0b013e3181 eee738

37. Malmgren K, Reuber M, Appleton R. Differential diagnosis of epilepsy. In: Oxford Textbook of Epilepsy and Epileptic Seizures. 2012:81-94.
38. Angus-Leppan H. Diagnosing epilepsy in neurology clinics: a prospective study. Seizure. 2008;17(5):431-436. doi:10.1016/j. seizure.2007.12.010

39. Brissart H, Planton M, Bilger M, et al. French neuropsychological procedure consensus in epilepsy surgery. Epilepsy Behav. 2019;100(Pt A):106522. doi:10.1016/j.yebeh.2019.106 522

40. Reinikainen KJ, Keränen T, Lehtinen JM, Kälviäinen R, Saari T, Riekkinen PJ. CT brain scan and EEG in the diagnosis of adult onset seizures. Epilepsy Res. 1987;1(3):178-184. doi:10.1016/ 0920-1211(87)90039-8

41. Bouma HK, Labos C, Gore GC, Wolfson C, Keezer MR. The diagnostic accuracy of routine electroencephalography after a first unprovoked seizure. Eur J Neurol. 2016;23(3):455-463. doi:10.1111/ ene. 12739

42. Gilbert DL, Sethuraman G, Kotagal U, Buncher CR. Metaanalysis of EEG test performance shows wide variation among studies. Neurology. 2003;60(4):564-570. doi:10.1212/01.WNL.00 00044152.79316 .27

43. Stafstrom CE, Carmant L. Seizures and epilepsy: an overview for neuroscientists. Cold Spring Harb Perspect Med. 2015;5(6): a022426. doi:10.1101/cshperspect.a022426

44. Akshoomoff N, Farid N, Courchesne E, Haas R. Abnormalities on the neurological examination and EEG in young children with pervasive developmental disorders. J Autism Dev Disord. 2007;37(5):887-893. doi:10.1007/s10 803-006-0216-9

45. Parikh R, Mathai A, Parikh S, Chandra Sekhar G, Thomas R. Understanding and using sensitivity, specificity and predictive values. Indian J Ophthalmol. 2008;56(1):45-50. doi:10.4103/ 0301-4738.37595

46. Shukla G, Bhatia M, Vivekanandhan S, et al. Serum prolactin levels for differentiation of nonepileptic versus true seizures: limited utility. Epilepsy Behav. 2004;5(4):517-521. doi:10.1016/ j.yebeh.2004.03.004

47. Javali M, Acharya P, Shah S, Mahale R, Shetty P, Rangasetty S. Role of biomarkers in differentiating new-onset seizures from psychogenic nonepileptic seizures. $J$ Neurosci Rural Pract. 2017;8(4):581-584. doi:10.4103/jnrp.jnrp_139_17

48. Woermann FG, Labudda K. [Clinical application of functional MRI for chronic epilepsy]. Der Radiologe. 2010;50(2):123-130. German. doi:10.1007/s00117-009-1894-z

49. Xiao F, An D, Zhou D. Functional MRI-based connectivity analysis: a promising tool for the investigation of the pathophysiology and comorbidity of epilepsy. Seizure. 2017;44:37-41. doi:10.1016/j.seizure.2016.10.003

50. Zhu Y, Zhu X. MRI-driven PET image optimization for neurological applications. Front Neurosci. 2019;13:782. doi:10.3389/ fnins.2019.00782

51. Juhász C, John F. Utility of MRI, PET, and ictal SPECT in presurgical evaluation of non-lesional pediatric epilepsy. Seizure. 2020;77:15-28. doi:10.1016/j.seizure.2019.05.008

52. Poduri A. When should genetic testing be performed in epilepsy patients? Epilepsy Curr. 2017;17(1):16-22. doi:10.5698/1535-751117.1.16

53. Balestrini S, Sisodiya SM. Pharmacogenomics in epilepsy. Neurosci Lett. 2018;667:27-39. doi:10.1016/j.neulet.2017.01. 014

54. Orsini A, Esposito M, Perna D, Bonuccelli A, Peroni D, Striano P. Personalized medicine in epilepsy patients. $J$ Transl Genet Genom. 2018. doi:10.20517/jtgg.2018.14

55. Truty R, Patil N, Sankar R, et al. Possible precision medicine implications from genetic testing using combined detection of sequence and intragenic copy number variants in a large cohort with childhood epilepsy. Epilepsia open. 2019;4(3):397-408. doi:10.1002/epi4.12348 
56. Sánchez Fernández I, Loddenkemper T, Gaínza-Lein M, Sheidley BR, Poduri A. Diagnostic yield of genetic tests in epilepsy: a meta-analysis and cost-effectiveness study. Neurology. 2019;92(5):e418-428. doi:10.1212/WNL.0000000000006850

57. Alqahtani F, Imran I, Pervaiz H, et al. Non-pharmacological interventions for intractable epilepsy. Saudi Pharm J. 2020;28:951-962. doi:10.1016/j.jsps.2020.06.016

58. Miller JW. Confirmed! Durable benefits of epilepsy surgery. Epilepsy Curr. 2014;14(1):26-28. doi:10.5698/1535-7597-14.1.26

59. Elliott R, Morsi A, Kalhorn S, et al. Vagus nerve stimulation in 436 consecutive patients with treatment-resistant epilepsy: long-term outcomes and predictors of response. Epilepsy Behav 2011;20:57-63. doi:10.1016/j.yebeh.2010.10.017

60. D’Andrea Meira I, Romão TT, Pires Do Prado HJ, Krüger LT, Pires MEP, da Conceição PO. Ketogenic diet and epilepsy: what we know so far. Front Neurosci. 2019;13:5. doi:10.3389/fnins. 2019.00005

61. Belousova ED, Zavadenko NN. [Epilepsy and autism spectrum disorders in children]. Zhurnal Nevrologii I Psikhiatrii Imeni SS Korsakova. 2018;118(5):80-85. Russian. doi:10.17116/ jnevro20181185280

62. Bonello M, Michael BD, Solomon T. Infective causes of epilepsy. Semin Neurol. 2015;35(3):235-244. doi:10.1055/s-0035-1552619

63. Jin J, Chen R, Xiao Z. Post-epilepsy stroke: a review. Expert Rev Neurother. 2016;16(3):341-349. doi:10.1586/14737175.2016.1151355

64. Sánchez-Carpintero Abad R, Sanmartí Vilaplana FX, Serratosa Fernández JM. Genetic causes of epilepsy. Neurologist. 2007;13 (Supplement 1):S47-51. doi:10.1097/NRL.0b013e31815bb07d

65. Sen A, Jette N, Husain M, Sander JW. Epilepsy in older people. Lancet. 2020;395(10225):735-748. doi:10.1016/S0140-6736(19) 33064-8

66. Rizvi S, Ladino LD, Hernandez-Ronquillo L, Téllez-Zenteno JF. Epidemiology of early stages of epilepsy: risk of seizure recurrence after a first seizure. Seizure. 2017;49:46-53. doi:10.1016/j. seizure.2017.02.006

67. Pohlmann-Eden B, Beghi E, Camfield C, Camfield P. The first seizure and its management in adults and children. BMJ. 2006;332(7537):339-342. doi:10.1136/bmj.332.7537.339

68. Sellier E, Uldall P, Calado E, et al. Epilepsy and cerebral palsy: characteristics and trends in children born in 1976-1998. Eur $J$ Paediatr Neurol. 2012;16(1):48-55. doi:10.1016/j.ejpn.2011. 10.003

69. Geladze T, Toidze O, Lomashvili ND. [Importance of timely diagnosis of benign childhood epilepsy with rolandic peaks] Zhurnal Nevropatologii I Psikhiatrii Imeni SS Korsakova. 1983;83(10):1492-1496. Russian.

70. Maguire MJ, Jackson CF, Marson AG, Nolan SJ. Treatments for the prevention of sudden unexpected death in epilepsy (SUDEP). Cochrane Database Syst Rev. 2016;7(7):Cd011792. doi:10.1002/ 14651858.CD011792.pub2

71. Shorvon S, Tomson T. Sudden unexpected death in epilepsy. Lancet. 2011;378(9808):2028-2038. doi:10.1016/S0140-6736(11) 60176-1

72. Antoniuk SA, Oliva LV, Bruck I, Malucelli M, Yabumoto S, Castellano JL. Sudden unexpected, unexplained death in epilepsy autopsied patients. Arq Neuropsiquiatr. 2001;59:40-45. doi:10. 1590/S0004-282X2001000100009

73. Ryvlin P, Cucherat M, Rheims S. Risk of sudden unexpected death in epilepsy in patients given adjunctive antiepileptic treatment for refractory seizures: a meta-analysis of placebo-controlled randomised trials. Lancet Neurol. 2011;10 (11):961-968. doi:10.1016/S1474-4422(11)70193-4

74. Hesdorffer DC, Tomson T, Benn E, et al. Do antiepileptic drugs or generalized tonic-clonic seizure frequency increase SUDEP risk? A combined analysis. Epilepsia. 2012;53(2):249-252. doi:10.1111/j.1528-1167.2011.03354.x
75. Hemery C, Ryvlin P, Rheims S. Prevention of generalized tonic-clonic seizures in refractory focal epilepsy: a meta-analysis. Epilepsia. 2014;55(11):1789-1799. doi:10.1111/ epi. 12765

76. Maguire MJ, Jackson CF, Marson AG, Nevitt SJ. Treatments for the prevention of sudden unexpected death in epilepsy (SUDEP). Cochrane Database Syst Rev. 2020;4(4):Cd011792. doi:10.1002/ 14651858.CD011792.pub3

77. Ramiro JI, Kumar A. Updates on management of anoxic brain injury after cardiac arrest. Mo Med. 2015;112(2):136-141.

78. Peljto AL, Barker-Cummings C, Vasoli VM, et al. Familial risk of epilepsy: a population-based study. Brain. 2014;137(Pt 3):79 5-805. doi:10.1093/brain/awt368

79. Schorner A, Weissert R. Patients with epileptic seizures and multiple sclerosis in a multiple sclerosis center in Southern Germany between 2003-2015. Front Neurol. 2019;10:613. doi:10.3389/fneur.2019.00613

80. Hamerle M, Ghaeni L, Kowski A, Weissinger F, Holtkamp M. Alcohol use and alcohol-related seizures in patients with epilepsy. Front Neurol. 2018;9:401. doi:10.3389/fneur.2018.00401

81. Lee SH, Byeon JH, Kim GH, Eun BL, Eun SH. Epilepsy in children with a history of febrile seizures. Korean J Pediatr. 2016;59(2):74-79. doi:10.3345/kjp.2016.59.2.74

82. Chaves J, Sander JW. Seizure aggravation in idiopathic generalized epilepsies. Epilepsia. 2005;46(s9):133-139. doi:10.1111/ j.1528-1167.2005.00325.x

83. Perucca E, Gram L, Avanzini G, Dulac O. Antiepileptic drugs as a cause of worsening seizures. Epilepsia. 1998;39(1):5-17. doi:10.1111/j.1528-1157.1998.tb01268.x

84. Bauer J. Seizure-inducing effects of antiepileptic drugs: a review. Acta Neurol Scand. 1996;94(6):367-377. doi:10.1111/j.16000404.1996.tb00047.x

85. Lee SK. Old versus new: why do we need new antiepileptic drugs? J Epilepsy Res. 2014;4(2):39-44. doi:10.14581/jer.14010

86. Almalag HM, Alzahrani H, Al-hussain F, et al. The impact of old versus new antiepileptic drugs on costs and patient reported outcomes among older adults. Geriatr Nurs. 2018;39(6):669-675. doi:10.1016/j.gerinurse.2018.05.001

87. Schmidt D. Drug treatment of epilepsy: are newer drugs more effective than older ones? In: Panayiotopoulos CP, editor. Atlas of Epilepsies. London: Springer London; 2010:1577-1582.

88. Patsalos PN, Berry DJ, Bourgeois BFD, et al. Antiepileptic drugs -best practice guidelines for therapeutic drug monitoring: a position paper by the subcommission on therapeutic drug monitoring, ILAE commission on therapeutic strategies. Epilepsia. 2008;49(7):1239-1276.

89. Schmidt D, Löscher W. New developments in antiepileptic drug resistance: an integrative view. Epilepsy Curr. 2009;9(2):47-52. doi:10.1111/j.1535-7511.2008.01289.x

90. Johannessen SI, Landmark CJ. Antiepileptic drug interactions principles and clinical implications. Curr Neuropharmacol. 2010;8(3):254-267. doi:10.2174/157015910792246254

91. Brodie MJ, Mintzer S, Pack AM, Gidal BE, Vecht CJ, Schmidt D. Enzyme induction with antiepileptic drugs: cause for concern? Epilepsia. 2013;54(1):11-27. doi:10.1111/j.1528-1167.2012.03671.x

92. Goldenberg MM. Overview of drugs used for epilepsy and seizures: etiology, diagnosis, and treatment. P T. 2010;35(7):392-415.

93. Hill DS, Wlodarczyk BJ, Palacios AM, Finnell RH. Teratogenic effects of antiepileptic drugs. Expert Rev Neurother. 2010;10 (6):943-959. doi:10.1586/ern.10.57

94. Etemad L, Moshiri M, Moallem SA. Epilepsy drugs and effects on fetal development: potential mechanisms. J Res Med Sci. 2012;17(9):876-881.

95. Koren G, Nava-Ocampo AA, Moretti ME, Sussman R, Nulman I. Major malformations with valproic acid. Can Fam Physician. 2006;52(4):441-442, 444, 447. 
96. Kelly TF. 11 - Maternal medical disorders of fetal significance. In: Gleason CA, Juul SE, editors. Avery's Diseases of the Newborn. 10th ed. Philadelphia: Content Repository Only!; 2018:104-118. e103.

97. Gupta M, Tripp J. Phenytoin. In: StatPearls. Treasure Island (FL): StatPearls Publishing Copyright (C) 2020, StatPearls Publishing LLC; 2020.

98. Patocka J, Wu Q, Nepovimova E, Kuca K. Phenytoin - An anti-seizure drug: overview of its chemistry, pharmacology and toxicology. Food Chem Toxicol. 2020;142:111393. doi:10.1016/j. fct.2020.111393

99. Maan JS, Duong TVH, Saadabadi A. Carbamazepine. In: StatPearls. Treasure Island (FL): StatPearls Publishing Copyright (C) 2020, StatPearls Publishing LLC; 2020.

100. Pellock JM. Carbamazepine side effects in children and adults. Epilepsia. 1987;28(s3):S64-S70. doi:10.1111/j.1528-1157.1987. tb05780.x

101. Meldrum BS, Rogawski MA. Molecular targets for antiepileptic drug development. Neurotherapeutics. 2007;4(1):18-61.

102. Greenfield LJ. Molecular mechanisms of antiseizure drug activity at GABAA receptors. Seizure. 2013;22(8):589-600. doi:10.1016/ j.seizure.2013.04.015

103. Mula M, Cavanna AE, Monaco F. Psychopharmacology of topiramate: from epilepsy to bipolar disorder. Neuropsychiatr Dis Treat. 2006;2(4):475-488. doi:10.2147/nedt.2006.2.4.475

104. Sommer BR, Mitchell EL, Wroolie TE. Topiramate: effects on cognition in patients with epilepsy, migraine headache and obesity. Ther Adv Neurol Disord. 2013;6(4):211-227. doi:10. $1177 / 1756285613481257$

105. Efendioglu M, Basaran R, Akca M, Ceman D, Demirtas C, Yildirim M. Combination therapy of gabapentin and $\mathrm{N}$-acetylcysteine against posttraumatic epilepsy in rats. Neurochem Res. 2020;45(8):1802-1812. doi:10.1007/s11064020-03042-x

106. Edwards LS, Beran RG. Lamotrigine - interactions matter! Epilepsy Behav. 2020;111:107333. doi:10.1016/j.yebeh.2020.10 7333

107. Zhang D, Qiu L, Zhang Y, Sang Y, Zheng N, Liu X. Efficacy and safety of sodium valproate plus lamotrigine in children with refractory epilepsy. Exp Ther Med. 2020;20(3):2698-2704. doi:10.3892/etm.2020.8984

108. Glauser TA, Cnaan A, Shinnar S, et al. Ethosuximide, valproic acid, and lamotrigine in childhood absence epilepsy: initial monotherapy outcomes at 12 months. Epilepsia. 2013;54(1):141-155. doi:10.1111/epi.12028

109. Shatara M, Regling K, Sabo C, Figueroa M, Taub JW, Rajpurkar M. Ethosuximide-induced thrombocytopenia: a case report. J Pediatr Hematol Oncol. 2019;41(5):420-421. doi:10. 1097/MPH.0000000000001310

110. Werbel T, Castrovinci P, Contestable J. Ethosuximide-induced drug reaction with eosinophilia and systemic symptoms with mediastinal lymphadenopathy. Pediatr Dermatol. 2019;36(4): e99-e101. doi:10.1111/pde.13848

111. Veroniki AA, Cogo E, Rios P, et al. Comparative safety of anti-epileptic drugs during pregnancy: a systematic review and network meta-analysis of congenital malformations and prenatal outcomes. BMC Med. 2017;15(1):95. doi:10.1186/s12916-0170845-1

112. Liu Z, Li J, Yang F, et al. Sodium valproate combined with levetiracetam in pediatric epilepsy and its influence on NSE, IL-6, hs-CRP and electroencephalogram improvement. Exp Ther Med. 2020;20(3):2043-2048. doi:10.3892/etm.20 20.8916

113. Rogawski MA, Heller AH. Diazepam buccal film for the treatment of acute seizures. Epilepsy Behav. 2019;101(Pt B):106537. doi:10.1016/j.yebeh.2019.106537
114. Fayyazi A, Khajeh A, Baghbani A. Comparison of effectiveness of topiramate and diazepam in preventing risk of recurrent febrile seizure in children under age of 2 years. Iran J Child Neurol. 2018;12(3):69-77.

115. Song L, Liu F, Liu Y, Zhang R, Ji H, Jia Y. Clonazepam add-on therapy for drug-resistant epilepsy. Cochrane Database Syst Rev. 2020;4(4):Cd012253. doi:10.1002/14651858.CD012253.pub3

116. Shangguan Y, Liao H, Wang X. Clonazepam in the treatment of status epilepticus. Expert Rev Neurother. 2015;15(7):733-740. doi:10.1586/14737175.2015.1056781

117. Kale R, Perucca E. Revisiting phenobarbital for epilepsy. BMJ. 2004;329(7476):1199-1200. doi:10.1136/bmj.329.7476.1199

118. Zhang LL, Zeng LN, Li YP. Side effects of phenobarbital in epilepsy: a systematic review. Epileptic Disord. 2011;13 (4):349-365. doi:10.1684/epd.2011.0444

119. Lyons JB, Liversedge LA. Primidone in the treatment of epilepsy. Br Med J. 1954;2(4888):625-627. doi:10.1136/bmj.2.4888.625

120. Mahendru RK, Mahendru S, Chandra R. Primidone in epilepsy-its value in fresh and refractory cases. Indian J Psychiatry. 1983;25 (3):223-225.

121. Rissardo JP, Caprara ALF. Pregabalin-associated movement disorders: a literature review. Brain Circ. 2020;6(2):96. doi:10.4103/ bc.bc_57_19

122. Singh R, Carson RP. Vigabatrin. In: StatPearls [Internet]. Treasure Island, FL: StatPearls Publishing; 2020.

123. Novak GP, Kelley M, Zannikos P, Klein B. Carisbamate (RWJ-333369). Neurotherapeutics. 2007;4(1):106-109. doi:10.10 16/j.nurt.2006.11.016

124. François J, Boehrer A, Nehlig A. Effects of carisbamate (RWJ-333369) in two models of genetically determined generalized epilepsy, the GAERS and the audiogenic Wistar AS. Epilepsia. 2008;49(3):393-399. doi:10.1111/j.1528-1167.2007.01 278.x

125. Almeida L, Soares-da-silva P. Eslicarbazepine acetate (BIA 2-093). Neurotherapeutics. 2007;4(1):88-96. doi:10.1016/j.nurt. 2006.10.005

126. Carreño M, Benbadis S, Rocha F, Blum D, Cheng H. Incidence of seizure exacerbation and seizures reported as adverse events during adjunctive treatment with eslicarbazepine acetate: a pooled analysis of three Phase III controlled trials. Epilepsia open. 2017;2(4):459-466. doi:10.1002/epi4.12083

127. Toledano R, Jovel CE, Jiménez-Huete A, et al. Efficacy and safety of eslicarbazepine acetate monotherapy for partial-onset seizures: experience from a multicenter, observational study. Epilepsy Behav. 2017;73:173-179. doi:10.1016/j.yebeh.2017.02.028

128. Toniolo S, Di Lorenzo F, Bozzali M, Yogarajah M. The impact of lacosamide on mood disorders in adult patients with epilepsy: a systematic review. Epilepsy Behav. 2020;111:107179. doi:10. 1016/j.yebeh.2020.107179

129. Vossler DG, Knake S, O’Brien TJ, et al. Efficacy and safety of adjunctive lacosamide in the treatment of primary generalised tonic-clonic seizures: a double-blind, randomised, placebo-controlled trial. J Neurol Neurosurg Psychiatry. 2020;91(10):1067-1075. doi:10.1136/jnnp-2020-323524

130. Schmitz B, Dimova S, Zhang Y, Chellun D, De Backer M, Gasalla T. Tolerability and efficacy of lacosamide and controlled-release carbamazepine monotherapy in patients with newly diagnosed epilepsy and concomitant psychiatric conditions: post hoc analysis of a prospective, randomized, double-blind trial. Epilepsy Res. 2020;159:106220. doi:10.1016/ j.eplepsyres.2019.106220

131. Sawicka KM, Florek-łuszczki M, Wawryniuk A, et al. Dronedarone (a multichannel blocker) enhances the anticonvulsant potency of lamotrigine, but not that of lacosamide, pregabalin and topiramate in the tonic-clonic seizure model in mice. Epilepsy Res. 2019;154:62-68. doi:10.1016/j.eplepsyres.2019.04.007 
132. Abarrategui B, García-García ME, Toledano R, Parejo-Carbonell B, Gil-Nagel A, García-Morales I. Lacosamide for refractory generalized tonic-clonic seizures of non-focal origin in clinical practice: a clinical and VEEG study. Epilepsy Behav Case Rep. 2017;8:63-65. doi:10.1016/j.ebcr.2017.08.001

133. Ozdemir O, Sari ME, Kurt A, Sakar VS, Atalay CR. Pregnancy outcome of 149 pregnancies in women with epilepsy: experience from a tertiary care hospital. Interv Med Appl Sci. 2015;7 (3):108-113. doi:10.1556/1646.7.2015.3.4

134. Meador K, Reynolds MW, Crean S, Fahrbach K, Probst C. Pregnancy outcomes in women with epilepsy: a systematic review and meta-analysis of published pregnancy registries and cohorts. Epilepsy Res. 2008;81(1):1-13. doi:10.1016/j.eplepsyres. 2008.04.022

135. Crawford P. Best practice guidelines for the management of women with epilepsy. Epilepsia. 2005;46(Suppl 9):117-124. doi:10.1111/j.1528-1167.2005.00323.x

136. Lutz B. On-demand activation of the endocannabinoid system in the control of neuronal excitability and epileptiform seizures. Biochem Pharmacol. 2004;68(9):1691-1698. doi:10.1016/j. bcp.2004.07.007

137. Karanian DA, Brown QB, Makriyannis A, Kosten TA, Bahr BA. Dual modulation of endocannabinoid transport and fatty acid amide hydrolase protects against excitotoxicity. $J$ Neurosci. 2005;25(34):7813-7820. doi:10.1523/JNEUROSCI.2347-05.2005

138. Colangeli R, Morena M, Pittman QJ, Hill MN, Teskey GC. Anandamide signaling augmentation rescues amygdala synaptic function and comorbid emotional alterations in a model of epilepsy. $J$ Neurosci. 2020;40(31):6068-6081. doi:10.1523/ JNEUROSCI.0068-20.2020

139. Sugiura T, Waku K. 2-Arachidonoylglycerol and the cannabinoid receptors. Chem Phys Lipids. 2000;108(1-2):89-106. doi:10.10 16/S0009-3084(00)00189-4

140. Ligresti A, Cascio MG, Di Marzo V. Endocannabinoid metabolic pathways and enzymes. Curr Drug Targets CNS Neurol Disord. 2005;4(6):615-623. doi:10.2174/156800705774933104

141. Ma L, Wang L, Yang F, et al. Disease-modifying effects of RHC80267 and JZL184 in a pilocarpine mouse model of temporal lobe epilepsy. CNS Neurosci Ther. 2014;20(10):905-915. doi:10.1111/cns.12302

142. Naydenov AV, Horne EA, Cheah CS, et al. ABHD6 blockade exerts antiepileptic activity in PTZ-induced seizures and in spontaneous seizures in R6/2 mice. Neuron. 2014;83(2):361-371. doi:10.1016/j.neuron.2014.06.030

143. Zareie P, Sadegh M, Palizvan MR. Investigating the effect of enzymatic elimination of endocannabinoids inhibitors on tonic-colonic seizure provoked by PTZ. Babol-Jbums. 2016;18 (12):49-56

144. Cilio MR, Thiele EA, Devinsky O. The case for assessing cannabidiol in epilepsy. Epilepsia. 2014;55(6):787-790. doi:10.1111/ epi. 12635

145. Dos Santos RG, Hallak JE, Leite JP, Zuardi AW, Crippa JA. Phytocannabinoids and epilepsy. J Clin Pharm Ther. 2015;40 (2):135-143. doi:10.1111/jcpt.12235

146. Ponton JA, Smyth K, Soumbasis E, et al. A pediatric patient with autism spectrum disorder and epilepsy using cannabinoid extracts as complementary therapy: a case report. J Med Case Rep. 2020;14(1):162. doi:10.1186/s13256-020-02478-7

147. Jones NA, Glyn SE, Akiyama S, et al. Cannabidiol exerts anti-convulsant effects in animal models of temporal lobe and partial seizures. Seizure. 2012;21(5):344-352. doi:10.1016/j. seizure.2012.03.001

148. Hill TD, Cascio MG, Romano B, et al. Cannabidivarin-rich cannabis extracts are anticonvulsant in mouse and rat via a CB1 receptor-independent mechanism. Br J Pharmacol. 2013;170 (3):679-692. doi:10.1111/bph.12321
149. Ehsan T, Fisher RS, Johns D, Lukas RJ, Blum D, Eskola J. Sensitivity and specificity of paired capillary prolactin measurement in diagnosis of seizures. $J$ Epilepsy. 1996;9(2):101-105. doi:10.1016/0896-6974(96)00006-0

150. Alving J. Serum prolactin levels are elevated also after pseudoepileptic seizures. Seizure. 1998;7(2):85-89.

151. Shah AK, Shein N, Fuerst D, Yangala R, Shah J, Watson C. Peripheral WBC count and serum prolactin level in various seizure types and nonepileptic events. Epilepsia. 2001;42 (11):1472-1475. doi:10.1046/j.1528-1157.2001.11901.x

152. Holtkamp M, Othman J, Buchheim K, Meierkord H. Diagnosis of psychogenic nonepileptic status epilepticus in the emergency setting. Neurology. 2006;66(11):1727-1729. doi:10.1212/01. wnl.0000218299.15988.9d

153. Goksu E, Oktay C, Kilicaslan I, Kartal M. Seizure or syncope: the diagnostic value of serum creatine kinase and myoglobin levels. Eur J Emerg Med. 2009;16(2):84-86. doi:10.1097/MEJ.0b 013e32830abe06

154. Yanagawa Y, Nishi K, Sakamoto T. Hyperammonemia is associated with generalized convulsion. Intern Med. 2008;47 (1):21-23. doi:10.2169/internalmedicine.47.0482

155. Liu KT, Lee CW, Yang SC, Yeh IJ, Lin TJ, Su CS. Postictal transient hyperammonemia as an indicator of seizure disorder. Eur Neurol. 2010;64(1):46-50. doi:10.1159/000315034

156. Tomita K, Otani N, Omata F, Ishimatsu S. Clinical significance of plasma ammonia in patients with generalized convulsion. Intern Med. 2011;50(20):2297-2301. doi:10.2169/internalmedicine.50.5950

157. Chadwick DW, Marson T, Kadir Z. Clinical administration of new antiepileptic drugs: an overview of safety and efficacy. Epilepsia. 1996;37(Suppl 6):S17-22. doi:10.1111/j.1528-1157.1996.tb06035.x

158. Rosenfeld WE, Sachdeo RC, Faught RE, Privitera M. Long-term experience with topiramate as adjunctive therapy and as monotherapy in patients with partial onset seizures: retrospective survey of open-label treatment. Epilepsia. 1997;38(Suppl 1):S34-36. doi:10.1111/j.1528-1157.1997.tb04516.x

159. Marson AG, Kadir ZA, Hutton JL, Dw C. The new antiepileptic drugs: a systematic review of their efficacy and tolerability. Epilepsia. 1997;38(8):859-880. doi:10.1111/j.1528-1157.1997.tb01251.x

160. Otoul C, Arrigo C, van Rijckevorsel K, French JA. Meta-analysis and indirect comparisons of levetiracetam with other second-generation antiepileptic drugs in partial epilepsy. Clin Neuropharmacol. 2005;28 (2):72-78. doi:10.1097/01.wnf.0000159956.87511.67

161. Sirven JI, Fife TD, Wingerchuk DM, Drazkowski JF. Secondgeneration antiepileptic drugs' impact on balance: a metaanalysis. Mayo Clin Proc. 2007;82(1):40-47. doi:10.1016/S00 25-6196(11)60965-8

162. Zaccara G, Gangemi PF, Cincotta M. Central nervous system adverse effects of new antiepileptic drugs. A meta-analysis of placebo-controlled studies. Seizure. 2008;17(5):405-421. doi:10. 1016/j.seizure.2007.12.003

163. Maguire MJ, Hemming K, Hutton JL, Marson AG. Reporting and analysis of open-label extension studies of anti-epileptic drugs. Epilepsy Res. 2008;81(1):24-29. doi:10.1016/j.eplepsyres.2008. 04.007

164. Jette N, Hemming K, Hutton JL, Marson AG. Topiramate add-on for drug-resistant partial epilepsy. Cochrane Database Syst Rev. 2008;3:Cd001417.

165. Luykx J, Mason M, Ferrari MD, Carpay J. Are migraineurs at increased risk of adverse drug responses? A meta-analytic comparison of topiramate-related adverse drug reactions in epilepsy and migraine. Clin Pharmacol Ther. 2009;85(3):283-288. doi:10. 1038/clpt.2008.203

166. Tachibana Y, Narukawa M. Investigation of influencing factors on higher placebo response in East Asian versus Western clinical trials for partial epilepsy: a meta-analysis. Clin Drug Investig. 2013;33(5):315-324. doi:10.1007/s40261-013-0077-x 
167. Pulman J, Jette N, Dykeman J, Hemming K, Hutton JL, Marson AG. Topiramate add-on for drug-resistant partial epilepsy. Cochrane Database Syst Rev. 2014;2:Cd001417.

168. Tan HJ, Singh J, Gupta R, de Goede C. Comparison of antiepileptic drugs, no treatment, or placebo for children with benign epilepsy with centro temporal spikes. Cochrane Database Syst Rev. 2014;2014(9):Cd006779.

169. Nolan SJ, Sudell M, Tudur Smith C, Marson AG. Topiramate versus carbamazepine monotherapy for epilepsy: an individual participant data review. Cochrane Database Syst Rev. 2016;12 (12):Cd012065.

170. Zhao T, Feng X, Liu J, Gao J, Zhou C. Evaluate the efficacy and safety of anti-epileptic medications for partial seizures of epilepsy: a network meta-analysis. J Cell Biochem. 2017;118 (9):2850-2864. doi:10.1002/jcb.25936

171. Zhuo C, Jiang R, Li G, et al. Efficacy and tolerability of second and third generation anti-epileptic drugs in refractory epilepsy: a network meta-analysis. Sci Rep. 2017;7(1):2535. doi:10.1038/ s41598-017-02525-2

172. Nevitt SJ, Sudell M, Weston J, Tudur Smith C, Marson AG. Antiepileptic drug monotherapy for epilepsy: a network meta-analysis of individual participant data. Cochrane Database Syst Rev. 2017;6(6):Cd011412. doi:10.1002/14651858.CD0114 12.pub2

173. Hu Q, Zhang F, Teng W, et al. Efficacy and safety of antiepileptic drugs for refractory partial-onset epilepsy: a network meta-analysis. J Neurol. 2018;265(1):1-11. doi:10.1007/s00415017-8621-x
174. Mohd-Tahir NA, Li SC. Meta-analyses of newer antiepileptic drugs as adjunct for treatment of focal epilepsy in children. Epilepsy Res. 2018;139:113-122. doi:10.1016/j.eplepsyres.2017. 11.007

175. Campos MSA, Ayres LR, Morelo MRS, Carizio FAM, Pereira LRL. Comparative efficacy of antiepileptic drugs for patients with generalized epileptic seizures: systematic review and network meta-analyses. Int $J$ Clin Pharm. 2018;40 (3):589-598. doi:10.1007/s11096-018-0641-9

176. Slater J, Chung S, Huynh L, et al. Efficacy of antiepileptic drugs in the adjunctive treatment of refractory partial-onset seizures: meta-analysis of pivotal trials. Epilepsy Res. 2018;143:120-129. doi:10.1016/j.eplepsyres.2017.10.004

177. Liu J, Wang LN, Wang YP. Topiramate for juvenile myoclonic epilepsy. Cochrane Database Syst Rev. 2019;1(1):Cd010008. doi:10.1002/14651858.CD010008.pub4

178. Lezaic N, Gore G, Josephson CB, Wiebe S, Jetté N, Keezer MR. The medical treatment of epilepsy in the elderly: a systematic review and meta-analysis. Epilepsia. 2019;60(7):1325-1340. doi:10.1111/epi.16068

179. Nordli DR, Bagiella E, Arzimanoglou A, et al. Meta-analysis of drug efficacy in adult vs pediatric trials of patients with PGTC seizures. Neurology. 2020;94(17):e1845-e1852. doi:10.1212/ WNL.0000000000009325

\section{Publish your work in this journal}

The Journal of Experimental Pharmacology is an international, peerreviewed, open access journal publishing original research, reports, reviews and commentaries on all areas of laboratory and experimental pharmacology. The manuscript management system is completely online and includes a very quick and fair peer-review system. Visit http://www.dovepress.com/testimonials.php to read real quotes from published authors. 